\title{
Environmental Correlates of Physiological Variables in Marsupials
}

\author{
P. C. Withers ${ }^{1, \star}$ \\ C. E. Cooper ${ }^{1,2,3, \dagger}$ \\ A. N. Larcombe ${ }^{1, *}$ \\ ${ }^{1}$ Zoology, School of Animal Biology M092, University of \\ Western Australia, Crawley, Western Australia 6009, \\ Australia; ${ }^{2}$ Centre for Behavioural and Physiological Ecology, \\ University of New England, Armidale, New South Wales \\ 2351, Australia; ${ }^{3}$ Department of Environmental Biology, \\ Curtin University of Technology, P.O. Box U1987, Perth, \\ Western Australia 6845, Australia
}

Accepted 10/12/2005; Electronically Published 4/20/2006

\begin{abstract}
We analyzed body temperature $\left(T_{\mathrm{b}}\right)$, basal metabolic rate (BMR), wet thermal conductance $\left(C_{\text {wet }}\right.$ ), and evaporative water loss (EWL) of marsupials by conventional and phylogenetically corrected regression. Allometric effects were substantial for BMR, $C_{\text {wet }}$, and EWL but not $T_{\mathrm{b}}$. There was a strong phylogenetic signal for mass and all physiological traits. A significant phylogenetic signal remained for BMR, $C_{\text {wet }}$, and EWL even after accounting for the highly significant phylogenetic signal of mass. $T_{\mathrm{b}}, \mathrm{BMR}, C_{\mathrm{wet}}$, and EWL allometric residuals were correlated with some diet, distribution, and climatic variables before and after correction for phylogeny. $T_{\mathrm{b}}$ residuals were higher for marsupials from arid environments (high $T_{\mathrm{a}}$ and more variable rainfall). The fossorial marsupial mole had a lower-than-expected $T_{\mathrm{b}}$ residual. The allometric slope for BMR was $0.72-0.75$. Residuals were consistently related to distribution aridity and rainfall variability, with species from arid and variable rainfall habitats having a low BMR, presumably to conserve energy in a low-productivity environment. The nectarivorous honey possum had a higher-than-expected BMR. For $C_{\text {wet }}$, the allometric slope was $0.55-0.62$; residuals were related to diet, with folivores having low and insectivores high $C_{\text {wet }}$ residuals. The allometric slope for EWL was $0.68-0.73$. EWL residuals were consistently correlated with rainfall variability, presumably facilitating maintenance of water balance during dry periods.
\end{abstract}

\footnotetext{
*Corresponding author; e-mail: pwithers@cyllene.uwa.edu.au.

†E-mail: c.cooper@curtin.edu.au.

${ }^{\ddagger}$ E-mail: ebmocral@graduate.uwa.edu.au.
}

Physiological and Biochemical Zoology 79(3):437-453. 2006. (C) 2006 by The University of Chicago. All rights reserved. 1522-2152/2006/7903-4183\$15.00

\section{Introduction}

A major objective of comparative physiology is elucidating factors that influence physiological variables for different species. Analyses that seek correlated evolution between physiological variables, climate, and life-history traits are likely to be especially worthwhile (Lovegrove 2003). For mammals, ambient temperature, circadian rhythm, activity level, growth, and digestion affect basic laboratory-measured physiological variables such as body temperature $\left(T_{\mathrm{b}}\right)$, evaporative water loss (EWL), thermal conductance $(C)$, and, in particular, metabolic rate (MR; Scholander et al. 1950a, 1950b; Aschoff 1981; McNab 2002). Measurement of basal metabolic rate (BMR) and other physiological variables under standardized conditions that satisfy the experimental requirements of BMR (animals are nongrowing, quiescent, postabsorptive, and within their thermoneutral range and inactive period) ensures that the resulting data are standardized between individuals and are therefore comparable both intra- and interspecifically. We examine here various biological and environmental factors that influence the basal $T_{\mathrm{b}}, \mathrm{BMR}, C_{\text {wet }}$, and EWL of marsupials.

Body mass has an important allometric effect on most physiological variables. It has a significant (but small) effect on $T_{\mathrm{b}}$ (Stahl 1967; Calder 1984; Withers et al. 2000) and highly significant effects on BMR (Kleiber 1932; Withers et al. 2000; White and Seymour 2003), $C_{\text {wet }}$ (Bradley and Deavers 1980; Aschoff 1981; Withers et al. 2000; Schleucher and Withers 2001), and EWL (Crawford and Lasiewski 1968; Hinds and MacMillen 1985, 1986; Williams 1996). Allometric effects are commonly accounted for by the standard procedure of $\log _{10}$ transformed least squares regression (e.g., Neter et al. 1996; Draper and Smith 1998; Zar 1999).

Interspecific variation remains even after allometric scaling has been accounted for, and some of this could be attributed to phylogenetic history, which should be considered when inferring adaptiveness to physiological traits (e.g., Felsenstein 1985; Elgar and Harvey 1987; Garland and Adolph 1994; Garland et al. 1999; Garland and Ives 2000). There are a number of approaches to phylogenetic analysis of physiological data (e.g., ANCOVA, nested ANOVA, independent contrasts, phylogenetic generalized least squares regression, autocorrelation, phylogenetic vector regression, multiple regression; see Felsenstein 1985; Harvey and Pagel 1991; Martins 1996; Martins and Hansen 1997; Garland et al. 1999; Garland and Ives 2000; Rohlf 2001; Rezende et al. 2004). We analyzed marsupial physiological 
variables by conventional least squares regression, autocorrelation (AC), phylogenetic vector regression (PVR), independent contrasts (IC), and phylogenetic generalized least squares regression (PGLS) to look for consistency of allometric patterns in marsupial physiological variables before and after phylogenetic correction by these different approaches.

Having accounted for allometric scaling and phylogeny, remaining variability in physiological data may be explained by environmental effects (e.g., environmental temperature or aridity), geographic distribution (e.g., arid or mesic environments), or natural history parameters (e.g., diet, foraging strategy, sociality, reproductive strategy). For example, there are a number of dietary, habit, life-history, and environmental correlates with BMR for mammals (e.g., McNab 1966, 1980, 1984, 1986a, 1986b, 2002; Lovegrove 2000, 2003) and birds (e.g., Bennett and Harvey 1987; McNab 1988; Tieleman and Williams 2000). McNab (1986a) noted that variability in mass-corrected BMR is particularly low for marsupials (compared with placental mammals) and that residual variability is correlated primarily with diet and activity. He suggested that marsupials have a low BMR if they feed on invertebrates, leaves of woody plants, or fruit, especially if they are sedentary and arboreal. However, he did not control for phylogeny and did not support life-history, dietary, or habit correlations with robust statistical analyses.

Here we examine the influence of body mass, phylogeny, diet, distribution, and climate on standardized laboratory physiological variables $\left(T_{\mathrm{b}}, \mathrm{BMR}, C_{\text {wet }}\right.$, and EWL) of marsupials. We use modern statistical approaches to examine and account for the effects of allometric scaling and phylogenetic history on these physiological variables and use ANOVA and regression to examine environmental correlates with mass-corrected and phylogenetically corrected residuals. It is important to note that synthetic studies such as ours, which use large data sets compiled from the literature, rely on the appropriate standardization of measurement conditions in the source studies (see Tieleman and Williams 2000; McKechnie and Wolf 2004).

\section{Material and Methods}

Data for body mass, BMR ( $n=61$ species), $T_{\mathrm{b}}(n=59), C_{\text {wet }}$ $(n=55)$, and EWL $(n=24)$ were obtained for marsupials from the published literature (Table A1). The majority of values for mass, BMR, $T_{\mathrm{b}}$, and $C_{\text {wet }}$ were obtained from Withers et al. (2000), with additional data from subsequent studies (Dawson et al. 2000; Cooper and Withers 2002; Nespolo et al. 2002). EWL data were obtained from the original published articles. Where there were multiple data for a species, the mean value for that species was used unless one measurement was inconsistent with the other measurements, in which case the inconsistent value was omitted. Only data for species measured under conditions that meet the criteria for BMR were included (i.e., resting, adult animals, in thermoneutrality during their inactive phase). All physiological data except $T_{\mathrm{b}}$ were expressed in ab- solute rather than mass-specific units (e.g., $\mathrm{mL} \mathrm{O}_{2} \mathrm{~h}^{-1}$ rather than $\mathrm{mL} \mathrm{O}_{2} \mathrm{~g}^{-1} \mathrm{~h}^{-1}$ for BMR) and along with body mass were $\log _{10}$-transformed.

Phylogenetic analyses were accomplished using a phylogenetic tree (Fig. 1) based on Kirsch et al. (1997), with additional data from Kirsch (1977), Edwards and Westerman (1995), Kirsch and Palma (1995), and Krajewski et al. (2000); the marsupial-placental divergence date (not included in Fig. 1) was 104 MYBP. We also considered alternative trees based on Asher et al. (2004) and Nilsson et al. (2004) because they had quite different basal branching patterns. However, these alternative trees had weaker phylogenetic signals $\left(k^{*}\right)$ and so were not used for phylogenetic correction (see "Results").

We used the randomization test for a phylogenetic signal to examine the resemblance among species for an individual trait (e.g., body mass) by randomly reallocating sets of trait values to tips of the tree 1,000 times (Blomberg et al. 2003). We also used the $k^{*}$ phylogenetic signal statistic to determine the phylogenetic strength of a single trait, modified from the PHYSIG.DOC Matlab module (Blomberg et al. 2003), where MSE* was calculated assuming a star phylogeny, and mean square error $(\mathrm{MSE}=$ residual sum of squares divided by its degrees of freedom) and expected $\mathrm{MSE}^{*} / \mathrm{MSE}$ were calculated using data transformed according to the phylogeny in Figure 1.

Conventional and phylogenetic regression procedures used mass as the $X$ variable ( $\log _{10}$-transformed) and a $Y$ trait that was also $\log _{10}$-transformed (except $T_{\mathrm{b}}$ ); that is, $Y=a+b X$, and the common statistics used to judge significance were the standard errors of the intercept $(a)$ and slope $(b)$, the regression coefficient $r^{2}$, the ANOVA $F$ and $P$ values, and the MSE. The mathematical procedures for conventional regression analysis are presented in many standard textbooks (e.g., Neter et al. 1996; Draper and Smith 1998; Zar 1999).

Phylogenetic correction by AC was used to analyze a single trait $(X$ or $Y)$ by maximizing the correlation between that trait and the trait premultiplied by a constant $\rho$ and a matrix representing the phylogenetic structure $(W)$, with the residuals $(\varepsilon)$ being the phylogenetically independent component of $X$ or $Y$; for example, $Y=\rho W Y+\varepsilon$ (Cheverud and Dow 1985). The phylogenetic matrix $W$ was the reciprocal of phylogenetic distances between species pairs (from Fig. 1); the diagonal (i.e., "similarities" for any species compared with itself, $w_{i i}$ ) was set to 1 . The value of $\rho$ was calculated by an iterative procedure, using the maximum-likelihood function; it was constrained to the range $1 / \lambda_{-\min }$ to $1 / \lambda_{+\min }$, where $\lambda_{-\min }$ and $\lambda_{+\min }$ were the negative and positive eigenvalues for $W$ closest to 0 (Cheverud and Dow 1985; Rohlf 2001). We regressed the $Y$-trait residuals against the mass residuals to obtain the phylogenetically corrected allometric relationship. The phylogenetic and masscorrected residuals from this regression were analyzed for diet and climate correlates by regression (climate variables) and ANOVA (diet and distribution). 


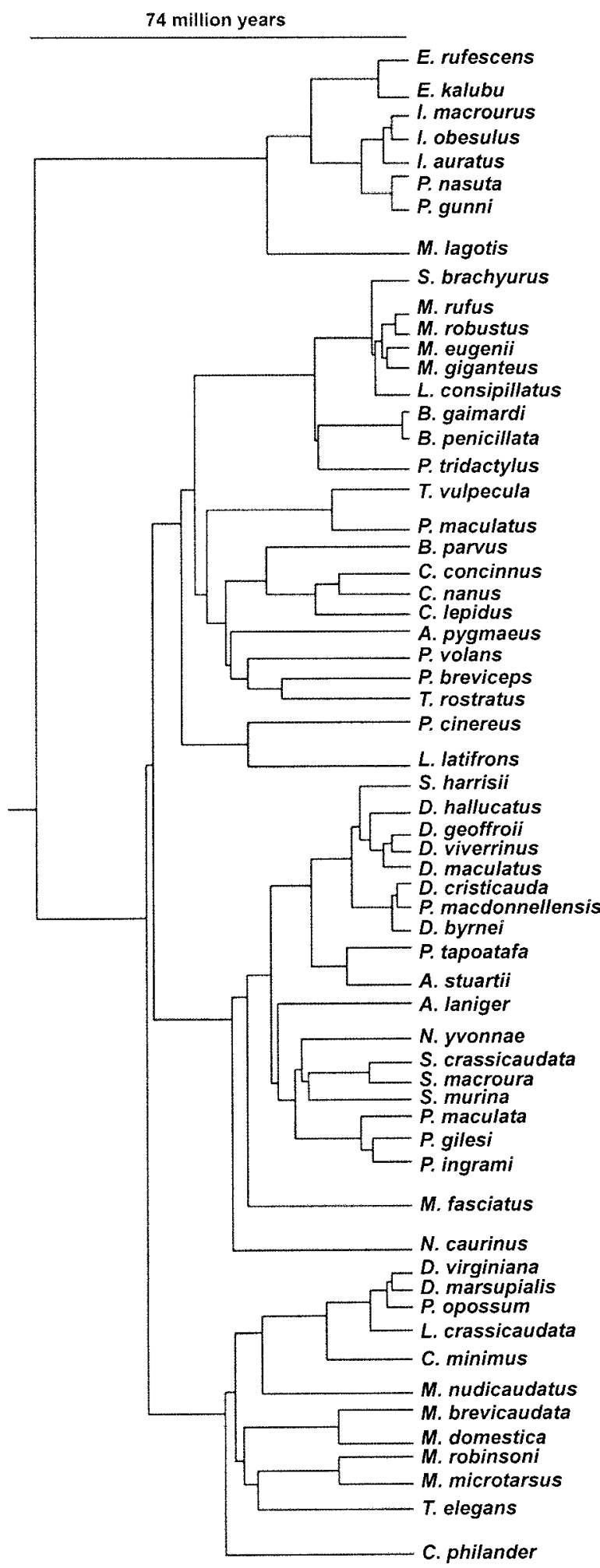

Figure 1. Phylogeny of marsupials used for phylogenetic analysis of physiological data, based on Kirsch et al. (1997); also Kirsch (1977), Edwards and Westerman (1995), Kirsch and Palma (1995), and Krajewski et al. (2000).
For PVR, the phylogenetic matrix was summarized using eigenvalues and eigenvectors; then the $X$ or $Y$ trait was multipleregressed against the significant eigenvectors (Diniz-Filho et al. 1998). The phylogenetic matrix consisted of distances between species pairs $\left(D_{i j}\right.$; from Fig. 1) transformed to $-0.5 D_{i j}^{2}$. The matrix was double-centered (rows and columns transformed to a mean of 0 ) before eigenvectors and eigenvalues were calculated. The most significant eigenvectors were selected using a scree plot and weighted by the square root of the corresponding eigenvalues for multiple regression against the $X$ or $Y$ trait. The residuals from this multiple regression were interpreted as the phylogenetically corrected trait values. We regressed $Y$-trait residuals against the mass residuals to obtain the phylogenetically corrected allometric relationship. The phylogenetic and mass-corrected residuals from this regression for the $Y$ trait were analyzed for diet and climate correlates.

IC was used to analyze $X$ and $Y$ traits separately, and then the $Y$-trait standardized contrasts were regressed against the $X$ trait (mass) contrasts (Felsenstein 1985; Garland et al. 1999). Calculations for IC were based on Garland and Ives (2000). Trait values for internal nodes of the phylogenetic tree (ancestral species) were estimated as the weighted average of the two daughter species (weights proportional to the inverse of branch lengths from node to daughters). ICs were then calculated as differences between sister taxa and standardized by branch lengths from node to daughter species. The regression of $Y$ trait standardized contrasts with positivized mass-standardized contrasts was calculated by linear regression forced through the origin. Predicted $Y$-trait tip values and, hence, residuals were calculated from the IC regression slope $\left(\beta_{1}\right)$, the $X$ trait $\left(X_{t}\right)$, and the basal node values $\left(X_{\mathrm{z}}\right.$ and $\left.Y_{\mathrm{z}}\right)$ as $\hat{Y}_{\mathrm{t}}=\beta_{1}\left(X_{\mathrm{t}}-X_{\mathrm{z}}\right)+$ $Y_{\mathrm{z}}$.

PGLS was used to analyze simultaneously an $X$ and a $Y$ trait by weighted regression (Draper and Smith 1998; Rohlf 2001). The weighting matrix was the variance-covariance matrix derived for phylogenetic distances from Figure 1 (see Rohlf 2001). PGLS was computed using the Cholesky decomposition matrix $(P)$ of the phylogenetic weighting matrix $\left(W=P^{\prime} \cdot P\right)$ and the transformed data $\left(P^{-1} X, P^{-1} Y\right)$ were analyzed by conventional regression through the origin $\left(P^{-1} Y=P^{-1} \beta X+P^{-1} \varepsilon\right)$. PGLS $Y$-trait residuals were "untransformed" by premultiplication with $P$ to obtain $\varepsilon$ (i.e., residuals fitted to the original $X$ and $Y$ scales). IC is a submodel of PGLS, and therefore the two approaches produce essentially identical results (Garland and Ives 2000; Rohlf 2001). We conducted both IC and PGLS analyses to verify that they were the same for our marsupial data, and because the analyses were essentially identical, we present the results for PGLS.

Results of the three phylogenetic methods are presented and compared to look for consistency in the outcomes because consistency between methods increases confidence in the conclusions. The statistical significance of allometry was determined from $r^{2}$ and ANOVA statistics (i.e., F-test, $P$ ). The sig- 
nificance of phylogenetic correction on the allometric relationships for $T_{\mathrm{b}}$, BMR, $C_{\text {wet }}$ and EWL was determined using an F-test comparing the MSE for the conventional allometric regression with the MSE for the phylogenetically corrected regression. The MSEs for conventional and phylogenetically corrected regressions were first corrected to a common scale by dividing the MSE by the total sum of squares $\left(\mathrm{SS}_{\text {total }}\right)$; this is equivalent to transforming the $X$ and $Y$ data so that their $\mathrm{SS}_{\text {total }}$ was 1 . The corrected MSEs were then compared using a variance test with the $F$ statistic; that is,

$$
F_{\mathrm{df}_{1}, \mathrm{df}_{2}}=\frac{\left(\mathrm{MSE} / \mathrm{SS}_{\mathrm{total}}\right)_{\text {conventional }}}{\left(\mathrm{MSE} / \mathrm{SS}_{\text {total }}\right)_{\text {phylogenetically corrected }}}
$$

where $\mathrm{df}_{1}$ and $\mathrm{df}_{2}$ are the degrees of freedom for the conventional and phylogenetically corrected regressions, respectively. (MSE/SS $\left.S_{\text {total }}\right)_{\text {conventional }}$ is expected to be greater than (MSE/ $\left.\mathrm{SS}_{\text {total }}\right)_{\text {phylogenetically corrected }}$ if there is a significant phylogenetic effect on the regression analysis, so $\left(\mathrm{MSE} / \mathrm{SS}_{\text {total }}\right)_{\text {conventional }}$ is in the numerator (and $F>1$ is expected).

Custom-written Visual Basic (version 6) programs were used for AC, IC, PGLS, the randomization test for phylogenetic signal, and $k^{*}$; all other calculations were done in Microsoft Excel and statistical analyses used StatistiXL (version 1.4).

Species were identified as regression outliers if their externally Studentized residual differed from 0 by more than the all-cases critical value for Studentized residuals in uncorrected and AC regressions and PVR ( $\alpha=0.05$; see StatistiXL [version 1.4]), and in PGLS using Grubbs's outlier test (Grubbs 1969; Stefansky 1972). Residuals were analyzed by ANOVA for influences of diet and distribution. For diet analyses, species were assigned to one of seven categories: folivore, herbivore, insectivore, vertebrativore, nectarivore, fungivore, or omnivore (Table B1). Two geographic distribution analyses were undertaken. First, species were classified as arid ( $90 \%$ of their geographic range had $<250 \mathrm{~mm}$ annual rainfall) or semiarid/mesic ( $90 \%$ of their range had $>250 \mathrm{~mm}$ annual rainfall). Second, the 500-mm isohyet (rather than the 250-mm isohyet) was used as the cutoff for classification as arid/semiarid or mesic. Data on diet and distribution were taken from Strahan (1991) and Walker (1975). Climate data (rainfall, temperature, altitude [Alt] and latitude [Lat]; Table B1) were downloaded from the National Climate Data Center (Asheville, NC) for the weather station closest to the reported source of each species (see Lovegrove 2003). If source information was unavailable and a reasonable estimate could not be made based on the species' distribution, then the species was excluded from this part of the study. Mean annual rainfall (MAR) was determined from the summed monthly rainfall data for all years of complete rainfall records. Rainfall variability (RV) was calculated as the coefficient of variation for MAR (SD/mean of the monthly averages). Mean temperature of the coldest month of the year $\left(T_{\text {cold }}\right)$, mean temperature of the warmest month of the year $\left(T_{\text {hot }}\right)$, and the mean yearly temperature $\left(T_{\mathrm{a}}\right)$ were all calculated from the mean monthly temperatures. Years with incomplete weather data were excluded. We examined the influence of climatic variables on the allometrically corrected residuals for each of the physiological variables (both before and after correction for phylogeny), using forward stepwise regression to account for possible multicollinearity of climatic variables.

\section{Results}

A strong phylogenetic signal was apparent for all of the physiological variables $(P<0.001)$ by the randomization test. The phylogenetic signal, assuming Brownian motion evolution, was less than expected (i.e., $\left.k^{*}<1\right)$ for $T_{\mathrm{b}}\left(k^{*}=0.36\right), C_{\text {wet }}(0.81)$, and EWL (0.67) and greater than expected (i.e., $>1$ ) for mass (1.16) and BMR (1.08). There was no significant phylogenetic signal for $T_{\mathrm{b}}$ mass-corrected residuals $\left(k^{*}=0.31 ; P=0.060\right)$, but there was for BMR $\left(k^{*}=0.35 ; P<0.023\right), C_{\text {wet }}\left(k^{*}=\right.$ $0.29 ; P=0.049)$, and EWL $\left(k^{*}=0.41 ; P=0.008\right)$ masscorrected residuals. There was a poorer phylogenetic signal for both mass and BMR using the alternative phylogenies based on Asher et al. (2004) and Nilsson et al. (2004). There was no significant phylogenetic signal for any of the climate variables by the randomization test except MAR $(P=0.017)$, and $k^{*}$ was substantially less than 1 for all climate variables $(\mathrm{MAR}=$ $0.35 ; \mathrm{RV}=0.30 ; T_{\text {cold }}=0.24 ; T_{\text {hot }}=0.24 ; T_{\mathrm{a}}=0.24 ;$ Alt $=$ 0.27 ; Lat $=0.315$ ).

There was substantial multicollinearity between most climatic variables. $T_{\mathrm{a}}$ was significantly correlated with all other variables (RV, $P=0.048$; MAR, $P=0.016$; Lat, $P<0.001 ; T_{\text {cold }}$, $P<0.001 ; T_{\text {hot }}, P<0.001$; Alt, $\left.P=0.010\right)$. Other correlations were as follows: $T_{\text {cold }}$ with MAR $(P<0.001)$, Lat $(P<0.001)$, $T_{\text {hot }}(P<0.001)$, and Alt $(P=0.043)$ and $T_{\text {hot }}$ with Lat $(P<$ $0.001)$ and Alt $(P=0.005)$.

\section{Body Temperature}

There was a significant positive relationship between mass and $T_{\mathrm{b}}$ (Fig. 2); $T_{\mathrm{b}}=34.1( \pm 0.37)+0.46( \pm 0.139) \log _{10} M\left(r^{2}=\right.$ $\left.0.16 ; F_{1,57}=11.0, P=0.002\right)$, but the allometric effect only explained $16 \%$ of the $T_{\mathrm{b}}$ variability. The significant allometric relationship remained after phylogenetic correction with PVR (slope $=0.449 ; F_{1,57}=7.2, P=0.010$ ) and PGLS (slope $=$ $\left.0.378 ; F_{1,57}=9.9, P=0.003\right)$, but not after correction with AC $\left(F_{1,57}=1.24, P=0.270\right)$. The allometric slope for $T_{\mathrm{b}}$ after PVR did not differ from the conventional regression $\left(F_{1,114}=\right.$ $0.003, P=0.959)$, and the slope for PGLS fell within the $95 \%$ confidence limits for the conventional regression. Phylogenetic correction did not significantly reduce the variability in $T_{\mathrm{b}}$ allometry (AC: $F_{57,57}=0.86, \quad P=0.72 ; \quad$ PVR: $F_{57,57}=0.94$, $P=0.72$; PGLS: $F_{57,57}=0.99, P=0.52$ ). The marsupial mole (Notoryctes caurinus) was an outlier in all regressions, having a significantly lower-than-predicted $T_{\mathrm{b}}$. 


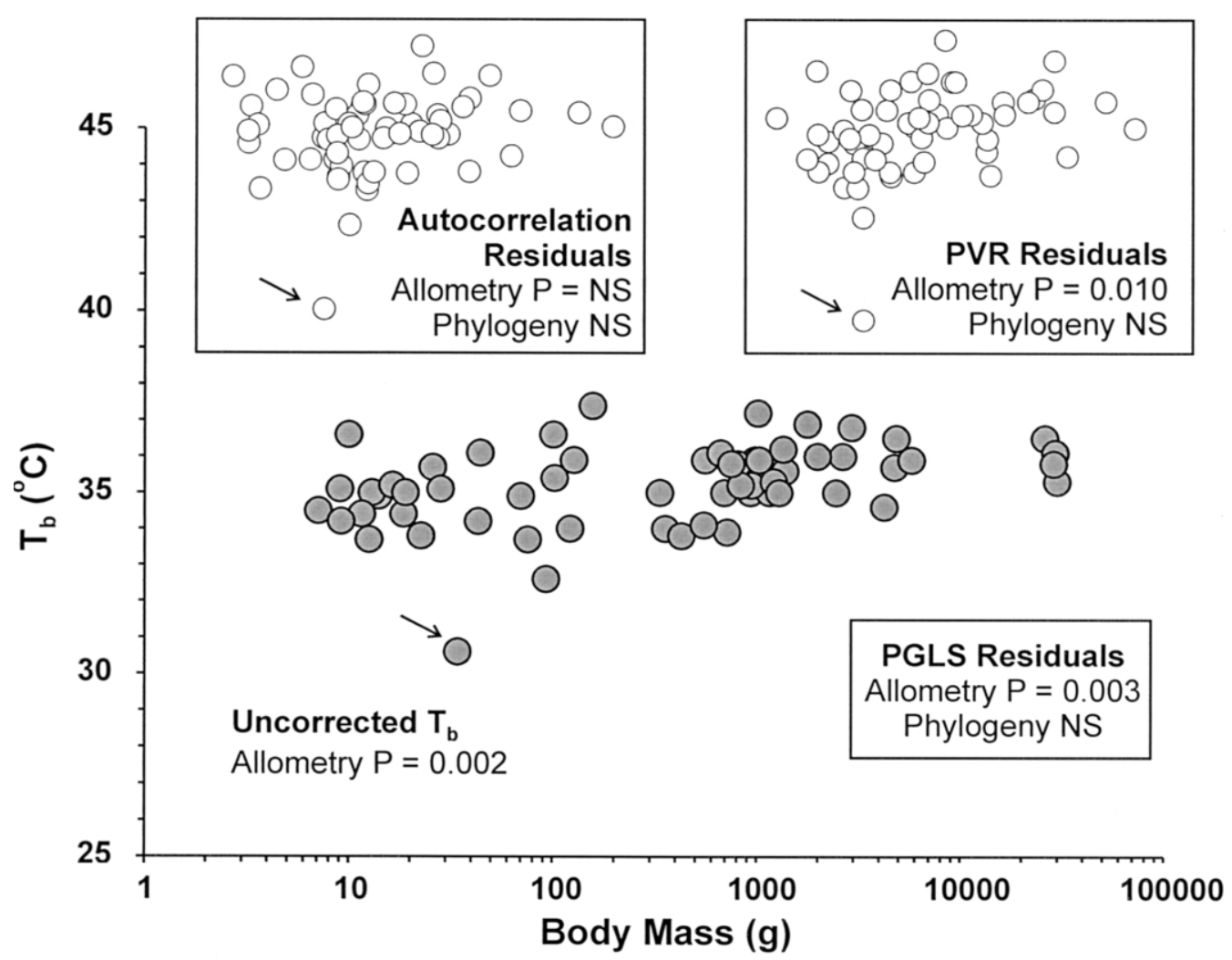

Figure 2. Conventional allometric analysis for body temperature $\left(T_{\mathrm{b}}\right)$ of marsupials. Insets show phylogenetically corrected regression analyses (phylogenetic generalized least squares [PGLS] regressions do not provide phylogenetically corrected $T_{\mathrm{b}}$ or mass values, so only statistical results are given). The consistent outlier (indicated by the arrow) is the marsupial mole.

The correlation of diet with residuals of the PGLS allometric relationship for marsupial $T_{\mathrm{b}}$ was significant $\left(F_{6,52}=2.4\right.$, $P=0.041$; Table 1), but that with conventional, AC, or PVR residuals was not. There was a significant relationship of $T_{\mathrm{b}}$ residuals with species distribution for $A C$ and PVR, with arid zones categorized as having $<250 \mathrm{~mm}$ annual rainfall (and also $<500 \mathrm{~mm}$ for PVR). Arid zone species had lower $T_{\mathrm{b}}$ residuals than non-arid zone species.

Conventional $T_{\mathrm{b}}$ residuals and those after AC, PVR, and PGLS phylogenetic correction had a weak but significant negative relationship with climatic variables by forward stepwise regression (Table 1). $T_{\text {cold }}$ was the significant climatic factor for conventional and PGLS regression, $T_{\text {hot }}$ was the significant factor for AC, and RV was the significant variable for PVR.

\section{Basal Metabolic Rate}

The conventional regression relationship for BMR of marsupials (Fig. 3) was $\log _{10} \mathrm{BMR}=0.40( \pm 0.033)+0.74( \pm$ $0.012) \log _{10} M\left(r^{2}=0.98 ; F_{1,59}=3,583, P<0.001\right)$. Allometry explained more than $98 \%$ of BMR variability. The one outlier (honey possum, Tarsipes rostratus) had a BMR significantly higher than predicted from mass. After correction of BMR to a standardized $T_{\mathrm{b}}$ of $35^{\circ}$ (assuming a $\mathrm{Q}_{10}$ of 2.5), the regression relationship for the data was $\log _{10} \mathrm{BMR}=0.45( \pm 0.029)+$ $0.72( \pm 0.011) \log _{10} M\left(r^{2}=0.99 ; F_{1,57}=4,434, P<0.001\right)$. The slope and intercept of this equation did not differ significantly from those for non- $T_{\mathrm{b}}$-corrected $\mathrm{BMR}$ data $\left(F_{1,114}=1.27\right.$, $P=0.262, F_{1,115}=0.25, P=0.620$, respectively), and there was no significant decrease in the variance $\left(F_{57,57}=1.22, P=\right.$ 0.226). Therefore, all subsequent discussion of BMR data will refer to non- $T_{\mathrm{b}}$-corrected data.

For AC-corrected BMR, there was a highly significant relationship between mass and $\operatorname{BMR}\left(r^{2}=0.97 ; F_{1,59}=1,733\right.$, $P<0.001)$; the slope was $0.72 \pm 0.017$. For PVR, the allometric effect was also highly significant $\left(r^{2}=0.98 ; F_{1,59}=2,294\right.$, $P<0.001)$, with a slope of $0.72 \pm 0.015$. The highly significant allometric effect remained for BMR data phylogenetically corrected with PGLS $\left(r^{2}=0.99 ; F_{1,59}=4,170, P<0.001\right)$, with a slope of $0.75 \pm 0.022$. Phylogenetic correction by AC $\left(F_{1,118}=0.504, \quad P=0.446\right)$ and $\operatorname{PVR}\left(F_{1,118}=0.824, \quad P=\right.$ $0.366)$ did not significantly alter the slope of the allometric equation for BMR, and the slope of 0.75 for PGLS fell within the $95 \%$ confidence limits for the uncorrected allometric slope. 
Table 1: Significant allometric and phylogenetic independent residuals for body temperature of marsupials, by ANOVA for diet and distribution aridity ( $<250-\mathrm{mm}$ isohyet, $<500 \mathrm{~mm}$ isohyet) and by regression for climate and geographic variables

\begin{tabular}{|c|c|c|c|c|}
\hline \multirow{2}{*}{$\begin{array}{l}\text { Variable and } \\
\text { Category }^{\mathrm{a}}\end{array}$} & \multicolumn{4}{|l|}{ ANOVA } \\
\hline & Residual & \multicolumn{3}{|l|}{$P$} \\
\hline \multicolumn{5}{|l|}{$\mathrm{AC}:$} \\
\hline \multicolumn{5}{|l|}{ Aridity $(<250 \mathrm{~mm})$ : } \\
\hline Arid & $-.623 \pm .426$ & \multirow[t]{2}{*}{.024} & & \\
\hline Semiarid $/$ mesic & $.159 \pm .133$ & & & \\
\hline \multicolumn{5}{|l|}{ PVR: } \\
\hline \multicolumn{5}{|l|}{ Aridity $(<250 \mathrm{~mm})$ : } \\
\hline Arid & $-.690 \pm .394$ & \multirow[t]{2}{*}{.005} & & \\
\hline Semiarid/mesic & $.176 \pm .114$ & & & \\
\hline \multicolumn{5}{|l|}{ Aridity $(<500 \mathrm{~mm})$ : } \\
\hline Arid/semiarid & $-.437 \pm .302$ & \multirow[t]{2}{*}{.028} & & \\
\hline Mesic & $.177 \pm .124$ & & & \\
\hline \multicolumn{5}{|l|}{ PGLS: } \\
\hline \multicolumn{5}{|l|}{ Diet: ${ }^{\mathrm{b}}$} \\
\hline Omnivore & $-.054 \pm .171$ & \multirow{7}{*}{.040} & & \\
\hline Insectivore & $.182 \pm .389$ & & & \\
\hline Herbivore & $.525 \pm .264$ & & & \\
\hline Folivore & $.924 \pm .246$ & & & \\
\hline Vertebrativore & $1.140 \pm .199$ & & & \\
\hline Fungivore & $1.189 \pm .502$ & & & \\
\hline \multirow[t]{3}{*}{ Nectarivore } & $1.322 \pm 1.010$ & & & \\
\hline & \multicolumn{4}{|l|}{ Regression } \\
\hline & Variable $^{\mathrm{a}}$ & Slope & $r^{2}$ & $P$ \\
\hline Conventional & $T_{\text {cold }}$ & $-.056 \pm .020$ & .124 & .008 \\
\hline $\mathrm{AC}$ & $T_{\text {hot }}$ & $-.072 \pm .029$ & .104 & .016 \\
\hline PVR & Rainfall variability & $-1.092 \pm .403$ & .122 & .044 \\
\hline PGLS & $T_{\text {cold }}$ & $-.056 \pm .020$ & .123 & .009 \\
\hline
\end{tabular}

There was no significant reduction in residual variance of the allometric relationship after phylogenetic correction by AC $\left(F_{59,59}=0.49, P=1.0\right), \operatorname{PVR}\left(F_{59,59}=0.65, P=0.95\right)$, or PGLS $\left(F_{59,59}=1.16, P=0.28\right)$. The honey possum was a significant outlier in all regressions, with a higher-than-predicted BMR.

Arid species $(<250 \mathrm{~mm}$ annual rainfall) had significantly lower conventional BMR residuals than mesic species (Table 2), but there was no relationship with diet. There was also a significant distribution effect after PGLS, with arid species ( $<250 \mathrm{~mm}$ annual rainfall) having lower residuals than mesic species. However, there was no significant effect of diet or distribution on BMR residuals after correction for phylogeny by AC, PVR, or PGLS. There was a weak but consistent significant negative relationship between residuals (both corrected and uncorrected for phylogeny) with RV by forward stepwise regression (Table 2).

\section{Wet Thermal Conductance}

The conventional regression for $C_{\text {wet }}$ of marsupials was $\log _{10} C_{\text {wet }}=1.32( \pm 0.057)+0.57( \pm 0.021) \log _{10} M \quad\left(r^{2}=0.93\right.$; $F_{1,53}=744, P<0.001$; Fig. 4$)$; mass explained $93 \%$ of $C_{\text {wet }}$ variability. There was a similar significant allometric effect after AC $\left(r^{2}=0.89 ; \quad F_{1,53}=450, \quad P<0.001\right)$, with a slope of $0.58 \pm 0.027$. PVR-corrected $C_{\text {wet }}$ was significantly influenced by mass $\left(r^{2}=0.91 ; F_{1,53}=515, P<0.001\right)$, with a slope of 


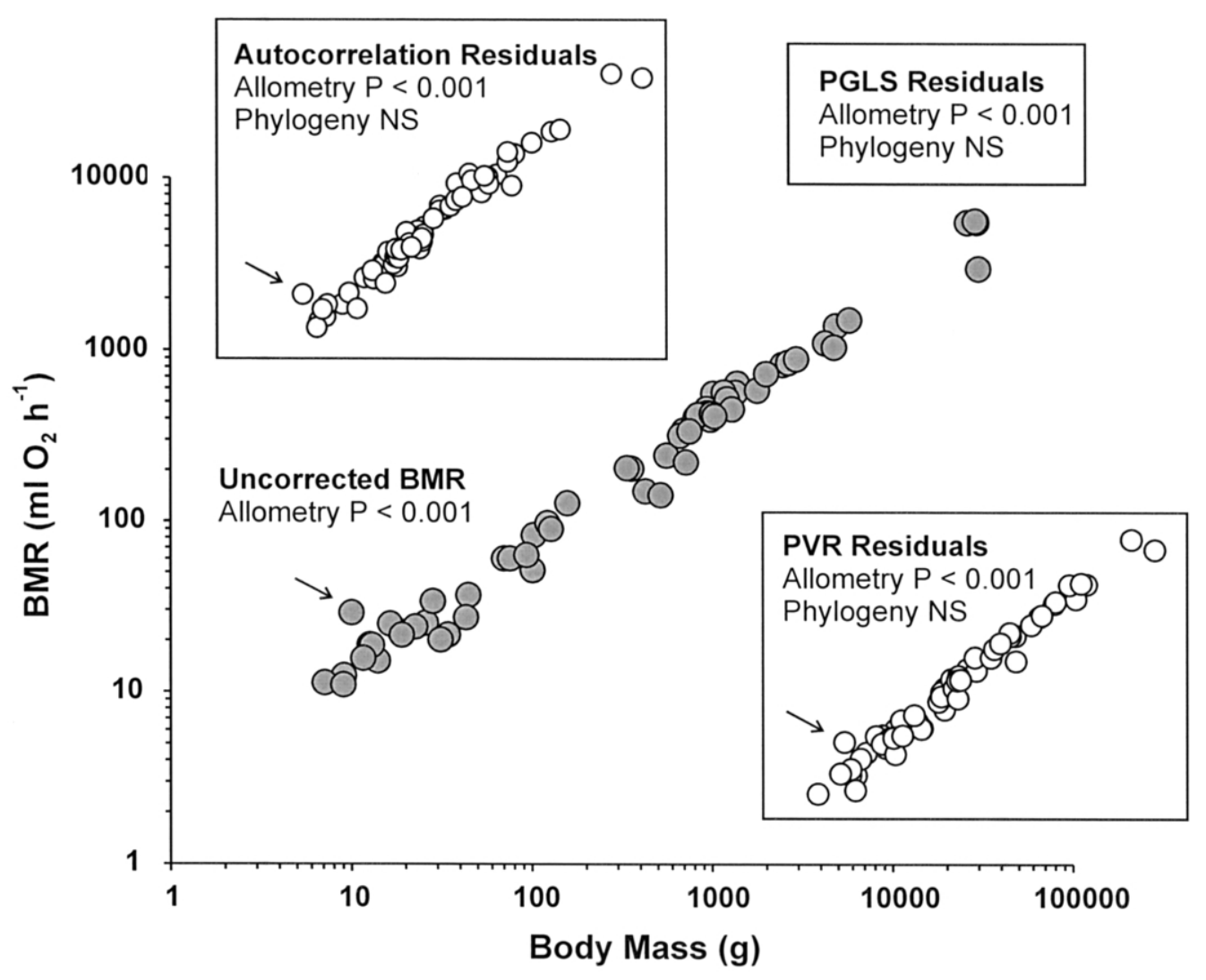

Figure 3. Conventional allometric analysis for basal metabolic rate (BMR) of marsupials. Insets show phylogenetically corrected regression analyses (PGLS regressions do not provide phylogenetically corrected BMR or mass values, so only statistical results are given). The consistent outlier (indicated by the arrow) is the honey possum.

$0.55 \pm 0.024$. The allometric effect was also highly significant for $C_{\text {wet }}$ data corrected by PGLS $\left(r^{2}=0.93 ; F_{1,53}=758, P<\right.$ 0.001 ), with a slope of $0.62 \pm 0.040$. Phylogenetic correction did not significantly alter the slope of the allometric equation for $C_{\text {wet }}$ with AC $\left(F_{1,106}=0.024, P=0.878\right)$ or $\operatorname{PVR}\left(F_{1,106}=\right.$ $0.507, P=0.478)$, and the slope for PGLS fell within the $95 \%$ confidence limits for the conventional allometric slope. There was no significant effect of phylogenetic correction on allometry for $\operatorname{AC}\left(F_{53,53}=0.63, P=0.95\right), \operatorname{PVR}\left(F_{53,53}=0.71, P=\right.$ $0.89)$, or PGLS $\left(F_{53,53}=1.02, P=0.47\right)$ corrected data. There were no outliers for conventional, PVR, or PGLS regressions, but the euro (Macropus robustus) was an outlier after AC, with a higher-than-expected $C_{\text {wet }}$.

There was a significant effect of diet for $C_{\text {wet }}$ residuals, both before $\left(F_{6,48}=3.68, P=0.004\right)$ and after correction for phylogeny by $\mathrm{AC}\left(F_{6,48}=3.43, P=0.007\right), \operatorname{PVR}\left(F_{6,48}=3.14\right.$, $P=0.011)$, and PGLS $\left(F_{6,48}=5.43, P<0.001\right.$; Table 3$)$. Folivores had lower $C_{\text {wet }}$ residuals than insectivores by all regression methods. Vertebrativores had lower $C_{\text {wet }}$ residuals than insectivores (conventional, PVR, and PGLS), omnivores had lower $C_{\text {wet }}$ residuals than insectivores (AC, PGLS), and vertebrativores and folivores had lower $C_{\text {wet }}$ residuals than omnivores (PGLS). There was a significant association of distribution with $C_{\text {wet }}$ residuals after correction by $\mathrm{AC}\left(F_{1,53}=7.1, P=0.010\right)$, with arid species ( $<250 \mathrm{~mm}$ annual rainfall) having higher $C_{\text {wet }}$ residuals than mesic species $(>250 \mathrm{~mm}) . C_{\text {wet }}$ residuals were not significantly correlated with climate variables either before or after correction for phylogeny.

\section{Evaporative Water Loss}

The regression for log-transformed mass and EWL of marsupials (Fig. 5) was $\log _{10} \mathrm{EWL}=0.96( \pm 0.092)+0.68( \pm$ $0.032) \log _{10} M\left(r^{2}=0.95 ; F_{1,22}=465, P<0.001\right)$, with mass explaining $95 \%$ of the variability in EWL. The allometric effect on EWL remained significant after $\mathrm{AC}\left(r^{2}=0.93 ; F_{1,22}=\right.$ 293, $P<0.001)$, with a slope of $0.69 \pm 0.04$. PVR-corrected EWL also had a highly significant allometry $\left(r^{2}=0.93\right.$; $\left.F_{1,22}=305, P<0.001\right)$, with a slope of $0.71 \pm 0.04$. The significant allometry remained after PGLS $\left(r^{2}=0.97, F_{1,22}=\right.$ $721, P<0.001$ ), with a slope of $0.73 \pm 0.043$. Phylogenetic correction by AC and PVR did not significantly alter the slope of 
Table 2: Significant allometric and phylogenetic independent residuals for basal metabolic rate of marsupials, by ANOVA for distribution aridity $(<250-\mathrm{mm}$ isohyet) and by regression for climate and geographic variables

\begin{tabular}{|c|c|c|c|c|}
\hline \multirow{2}{*}{$\begin{array}{l}\text { Variable and } \\
\text { Category }^{\mathrm{a}}\end{array}$} & \multicolumn{4}{|l|}{ ANOVA } \\
\hline & Residual & $P$ & & \\
\hline \multicolumn{5}{|l|}{ Conventional: } \\
\hline Arid & $-.052 \pm .035$ & .031 & & \\
\hline Semiarid/mesic & $.013 \pm .012$ & & & \\
\hline \multicolumn{5}{|l|}{ PGLS: } \\
\hline Arid & $-.025 \pm .086$ & .025 & & \\
\hline \multirow[t]{3}{*}{ Semiarid/mesic } & $.044 \pm .012$ & & & \\
\hline & Regression & & & \\
\hline & Variable $^{\mathrm{a}}$ & Slope & $r^{2}$ & $P$ \\
\hline Conventional & Rainfall variability & $-.126 \pm .035$ & .190 & $<.001$ \\
\hline $\mathrm{AC}$ & Rainfall variability & $-.098 \pm .040$ & .097 & .018 \\
\hline PVR & Rainfall variability & $-.107 \pm .035$ & .144 & .004 \\
\hline PGLS & Rainfall variability & $-.104 \pm .037$ & .128 & .006 \\
\hline
\end{tabular}

Note. AC = autocorrelation; PGLS = phylogenetic generalized least squares regression; $\mathrm{PVR}=$ phylogenetic vector regression.

${ }^{\text {a }}$ See Table B1.

the allometric equation for $\operatorname{EWL}\left(F_{1,44}=0.04, P=0.844\right.$; $\left.F_{1,44}=0.18, P=0.674\right)$, and the PGLS slope fell within the 95\% confidence limits for the slope of the conventional allometric equation. Phylogenetic correction did not significantly reduce the variability in the relationship between mass and EWL after $\mathrm{AC}\left(F_{22,22}=0.65, P=0.843\right)$, $\operatorname{PVR}\left(F_{22,22}=0.67, P=\right.$ $0.820)$, or PGLS $\left(F_{22,22}=1.53, P=0.164\right)$. There were no outliers after correction by PVR or PGLS, but the Tasmanian devil (Sarcophilus harrisii) was an outlier for conventional and AC regressions, with a higher-than-predicted EWL.

There was no significant effect of either diet or distribution on EWL residuals for marsupials before or after phylogenetic correction. EWL residuals were, however, negatively correlated with one climatic variable, RV, for all regression methods (Table 4).

\section{Discussion}

Many comparative physiological studies seek correlates between physiological parameters and mass, phylogeny, diet, habitat, or climate. For example, the classical study of Lasiewski and Dawson (1967) recognized a phylogenetically based distinction between BMRs of passerine and nonpasserine birds, while Bennett and Harvey (1987) and McNab (1988) correlated a number of diet and habitat traits with avian BMR variability. For mammals, Hayssen and Lacy (1985) identified taxonomic differences in BMR among mammalian orders, and Elgar and Harvey (1987) described the influence of phylogeny, diet, and habitat on BMR. McNab (1966, 1980, 1984, 1986a, 1986b) and Harvey et al. (1991) have suggested that a variety of traits (in particular diet, activity, and reproduction) affect mammalian energetics, while recent studies by Lovegrove $(2000,2003)$ have described zoogeographic and climatic patterns in mammalian BMR. However, in a smaller taxonomic clade-rodents—Rezende et al. (2004) found no significant dietary or climatic correlations with BMR after mass and phylogenetic correction (see their Table 5). Here, we have focused on another clade of mammals, the marsupials, and found strong allometric patterns in BMR, $C_{\text {wet }}$, and EWL; a strong phylogenetic pattern in body mass; mass-independent phylogenetic patterns in BMR, $C_{\text {wet }}$, and EWL; and some correlates of $T_{\mathrm{b}}, \mathrm{BMR}, C_{\mathrm{wet}}$, and EWL allometric residuals with diet and climate.

\section{Allometry}

The allometric exponents of $0.72-0.75$ for BMR $\left(r^{2}>0.97\right)$, 0.55-0.62 for $C_{\text {wet }}\left(r^{2}>0.89\right)$, and $0.68-0.73$ for EWL $\left(r^{2}>\right.$ $0.95)$ and the weak allometric relationship for $T_{\mathrm{b}}$ that we report for marsupials are consistent with expectations (Withers et al. 2000; but see Morrison and Ryser 1952; Calder 1984, calculated from Dawson and Hulbert 1970; Schmidt-Nielsen 1984; Lovegrove 2003). Phylogenetic correction did not significantly change any of these allometric slopes. A strong allometry has been recognized for BMR of mammals and birds since the pioneering scaling studies of Brody and Proctor (1932) and Kleiber (1932), as well as for other physiological parameters such as $C_{\text {wet }}$ (Bradley and Deavers 1980; Aschoff 1981; Withers 


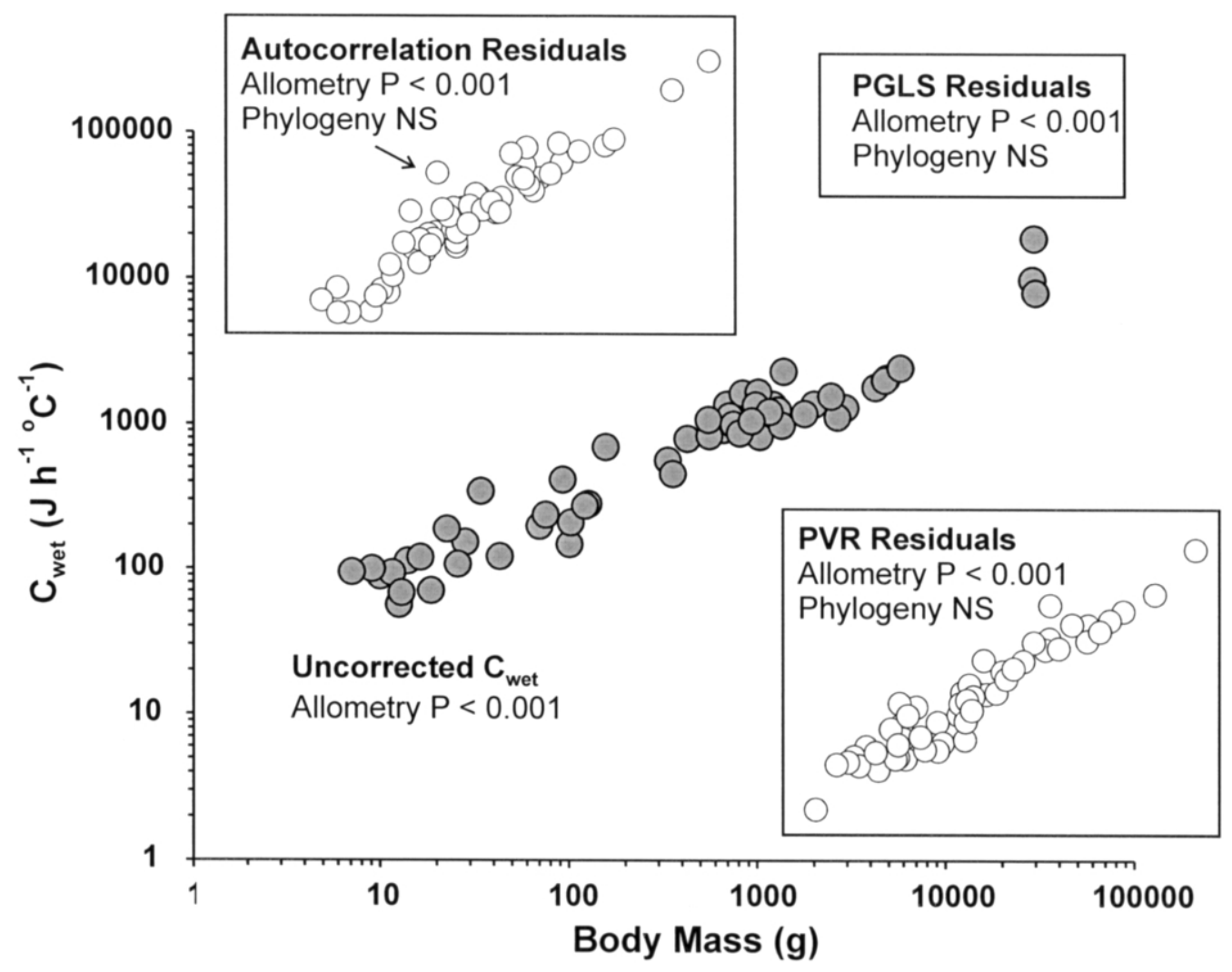

Figure 4. Conventional allometric analysis for wet thermal conductance $\left(C_{\text {wet }}\right)$ of marsupials. Insets show phylogenetically corrected regression analyses (PGLS regressions do not provide phylogenetically corrected $C_{\text {wet }}$ or mass values, so only statistical results are given). The outlier (indicated by the arrow) is the euro.

et al. 2000; Schleucher and Withers 2001) and EWL (Crawford and Lasiewski 1968; Hinds and MacMillen 1985, 1986; Williams 1996). However, the explanation for allometric exponents remains controversial (see McNab 2002; White and Seymour 2003).

\section{Phylogeny}

The strong phylogenetic signal for mass and all of the physiological variables examined here for marsupials (i.e., random simulation $P<0.05)$ is expected. A comprehensive review of phylogenetic signal for mass, physiological traits, and other traits indicated a significant phylogenetic signal in a wide range of animals for $85 \%$ of 27 mass and mass-related traits, $75 \%$ of 12 physiological traits, and $69 \%$ of 52 other traits (Blomberg et al. 2003). The phylogenetic signal was generally less than expected $\left(k^{*}<1\right)$ from Brownian motion evolution $(67 \%$ for mass and mass-related traits, $67 \%$ for physiological traits, and $83 \%$ for other traits; Blomberg et al. 2003). This was also the case for marsupial $T_{\mathrm{b}}, C_{\text {wet }}$, and EWL (i.e., $k^{*}<1$ ) but not mass and BMR (i.e., $k^{*}>1$ ). Only one climatic variable (MAR) had a significant phylogenetic signal. This is in contrast to the strong phylogenetic patterns for diet and environmental variables (e.g., latitude, temperature, rainfall) for rodents (Rezende et al. 2004).

It is instructive to examine the residuals of the highly significant allometric relationships for BMR, $C_{\text {wet }}$, and EWL for a phylogenetic signal because mass is a large component of the variability in these traits (see "Allometry"), and its strong phylogenetic signal is therefore a large part of the signal for these traits. A significant phylogenetic signal remained after accounting for mass, indicating mass-independent phylogenetic inertia in these three traits. Despite the phylogenetic signal in individual traits, none of the phylogenetic methods used here (AC, PVR, PGLS) significantly reduced the variability of the allometric relationships for $T_{\mathrm{b}}, \mathrm{BMR}, C_{\text {wet }}$, or EWL compared with conventional regression. This suggests that the phylogenetic pattern is consistent for mass and physiological traits in marsupials.

\section{Allometric and Phylogenetic Corrected Residuals}

Having accounted for the majority of the variability in physiological parameters (other than $T_{\mathrm{b}}$ ) by body mass and phylogeny for marsupials, we examined the remaining variance for 
Table 3: Significant allometric and phylogenetic independent residuals for wet thermal conductance of marsupials, by ANOVA for diet and distribution aridity $(<250-\mathrm{mm}$ isohyet)

\begin{tabular}{|c|c|c|}
\hline \multirow{2}{*}{$\begin{array}{l}\text { Variable and } \\
\text { Category }^{\mathrm{a}}\end{array}$} & \multicolumn{2}{|l|}{ ANOVA } \\
\hline & Residual & $P$ \\
\hline \multicolumn{3}{|l|}{ Conventional: } \\
\hline \multicolumn{3}{|l|}{ Diet: } \\
\hline Folivore $^{\mathrm{A}}$ & $-.165 \pm .035$ & .004 \\
\hline Vertebrativore $^{\mathrm{B}}$ & $-.122 \pm .038$ & \\
\hline Nectarivore & $-.019 \pm .069$ & \\
\hline Omnivore & $-.009 \pm .024$ & \\
\hline Fungivore & $.088 \pm .116$ & \\
\hline Herbivore & $.093 \pm .041$ & \\
\hline Insectivore ${ }^{\mathrm{AB}}$ & $.093 \pm .108$ & \\
\hline \multicolumn{3}{|l|}{$\mathrm{AC}$} \\
\hline \multicolumn{3}{|l|}{ Diet: } \\
\hline Folivore $^{\mathrm{A}}$ & $-.173 \pm .047$ & .007 \\
\hline Fungivore & $-.064 \pm .066$ & \\
\hline Omnivore $^{\mathrm{B}}$ & $-.034 \pm .023$ & \\
\hline Vertebratore & $-.024 \pm .034$ & \\
\hline Nectarivore & $.024 \pm .060$ & \\
\hline Herbivore & $.105 \pm .149$ & \\
\hline Insectivore $^{\mathrm{AB}}$ & $.114 \pm .040$ & \\
\hline \multicolumn{3}{|l|}{ Aridity: } \\
\hline Mesic & $-.027 \pm .020$ & .010 \\
\hline Arid & $.097 \pm .053$ & \\
\hline \multicolumn{3}{|l|}{ PVR: } \\
\hline \multicolumn{3}{|l|}{ Diet: } \\
\hline Folivore $^{\mathrm{A}}$ & $-.139 \pm .068$ & .011 \\
\hline Vertebrativore $^{\mathrm{B}}$ & $-.110 \pm .042$ & \\
\hline Omnivore & $-.012 \pm .018$ & \\
\hline Fungivore & $.053 \pm .116$ & \\
\hline Nectarivore & $.056 \pm .051$ & \\
\hline Insectivore $^{\mathrm{AB}}$ & $.075 \pm .042$ & \\
\hline Herbivore & $.104 \pm .108$ & \\
\hline \multicolumn{3}{|l|}{ PGLS: } \\
\hline \multicolumn{3}{|l|}{ Diet: } \\
\hline Folivore ${ }^{\mathrm{AB}}$ & $-.212 \pm .036$ & $<.001$ \\
\hline Vertebrativore $^{\mathrm{CD}}$ & $-.141 \pm .034$ & \\
\hline Omnivore ${ }^{\mathrm{BDE}}$ & $-.013 \pm .023$ & \\
\hline Herbivore & $.012 \pm .103$ & \\
\hline Nectarivore & $.021 \pm .087$ & \\
\hline Fungivore & $.058 \pm .115$ & \\
\hline Insectivore $^{\mathrm{ACE}}$ & $.125 \pm .041$ & \\
\hline
\end{tabular}

Note. $\mathrm{AC}=$ autocorrelation; $\mathrm{PVR}=$ phylogenetic vector regression; PGLS $=$ phylogenetic generalized least squares regression. Superscript letters indicate a significant differences between categories (Student-Newman-Keuls post hoc test, $P<0.05)$.

${ }^{\text {a }}$ See Table B1. relationships with diet, geographic distribution, and climatic variables. Both ANOVA analysis and climate regressions indicate that marsupials from arid environments (higher ambient temperatures and lower and more variable rainfall) have lower body temperatures than those from mesic environments (cooler ambient temperatures and higher and more predictable rainfall; Table 1). Early studies suggested no pattern in $T_{\mathrm{b}}$ for mammals from cold and warm environments (Scholander et al. 1950a; Irving and Krog 1954), but McNab (1970) suggested that mammalian $T_{\mathrm{b}}$ shows some adaptive variation with diet, habitat, and climate after BMR, $C_{\text {wet }}$, and mass are accounted for. Lovegrove (2003) also found that $T_{\mathrm{b}}$ of small mammals varied between geographic zones and increased with latitude (as we also observed for marsupials because $T_{\text {cold }}$ and $T_{\text {hot }}$ are correlated with latitude). Presumably, a low $T_{\mathrm{b}}$ results in significant energy and water savings in arid environments with low primary productivity and uncertain water availability. The marsupial mole was the only significant outlier, and its low $T_{\mathrm{b}}$ is presumably related to its highly specialized fossorial habit (Withers et al. 2000).

Marsupials appear to be metabolically conservative. After the effects of mass and phylogeny are removed, less than $4 \%$ of BMR variation remains to be correlated with diet, distribution, or environmental parameters and to identify outlier species. The only significant effect by ANOVA was for distribution, with arid zone species ( $<250 \mathrm{~mm}$ MAR) having a lower BMR than semiarid/mesic species (Table 2). This is the expected pattern reported for various mammal and bird species (e.g., Hart 1971; Bradley and Yousef 1972; Tieleman and Williams 2000; Schleucher and Withers 2002). A different pattern is noted below, using regression of climatic variables, where RV (not MAR) is best correlated with BMR residuals by all regression types.

Regression analysis of climate was more powerful and consistent than ANOVA for detecting environmental correlates of $\mathrm{BMR}$, resulting in a consistent and strong relationship between BMR residuals and RV (Table 2). This is probably because quantitative values rather than categorical groups are used for environmental variables. Climate regression analysis also accounts for intraspecific variation because climate data were actual measurements for the capture location of the individual study animals rather than an estimate based on the total distribution of the species (as in our ANOVA analysis). For rodents, there were no climatic correlations for BMR after accounting for mass and phylogeny (two-tailed $P>0.05$; Rezende et al. 2004). Lovegrove (2003) found no relationship with BMR and RV for Australian mammals, but he pooled marsupial and placental mammals (which will increase the variation in the data because of the well-documented differences in BMR between the two groups), and we included South American marsupials in our study. However, for small mammals in general, he found that BMR was positively related to mean annual temperature and negatively related to ambient temperature and RV (and hence unpredictable resource availability). Our consistent 


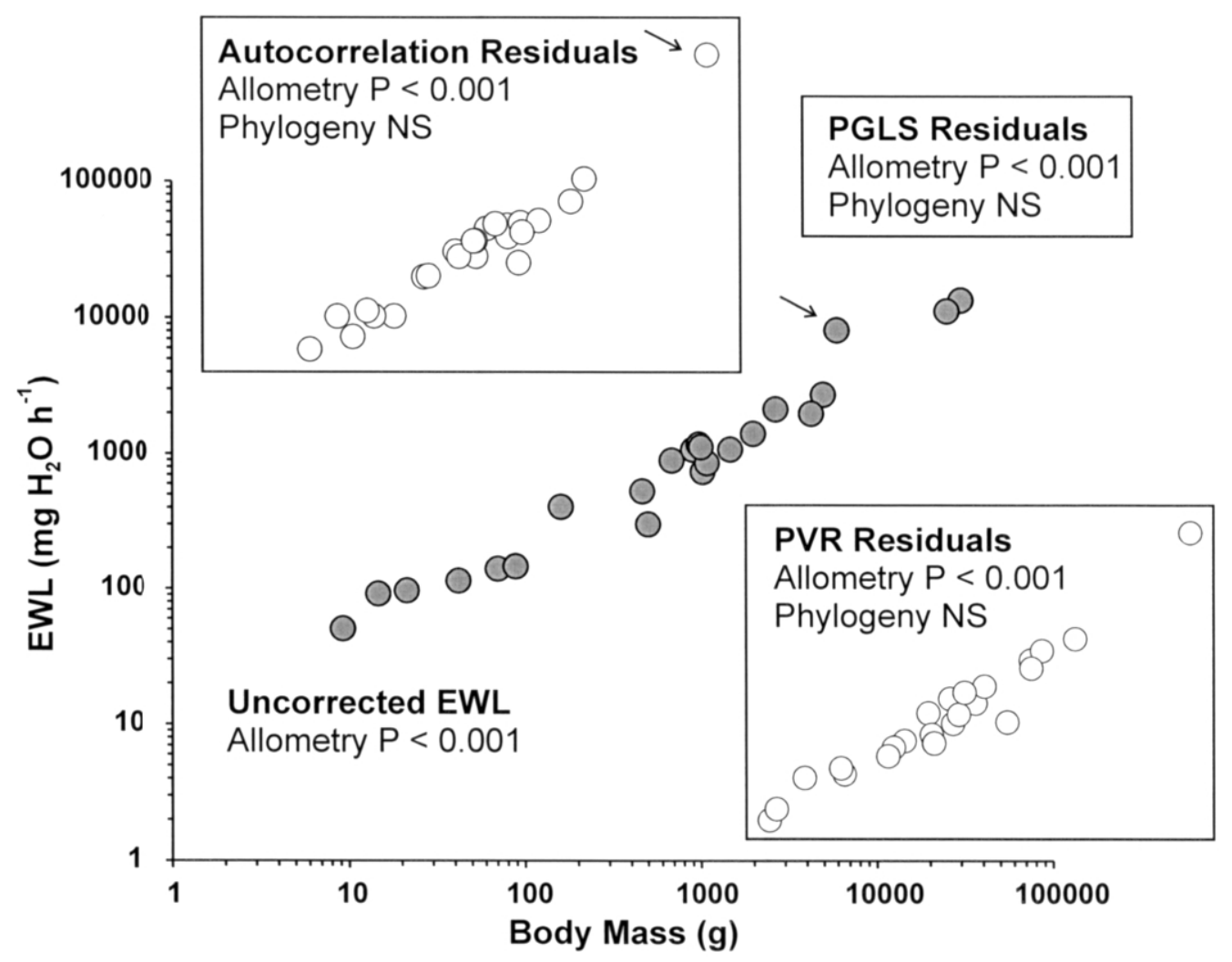

Figure 5. Conventional allometric analysis for evaporative water loss (EWL) of marsupials. Insets show phylogenetically corrected regression analyses (PGLS regressions do not provide phylogenetically corrected EWL or mass values, so only statistical results are given). The outlier (indicated by the arrow) is the Tasmanian devil.

pattern of low BMR for marsupials in high-RV areas is presumably related to reduced energy requirements in areas with low and unpredictable primary productivity (see Lovegrove 2000).

Interestingly, none of the BMR residuals either before or after phylogenetic correction showed any correlation with diet when analyzed by ANOVA. This is in contrast to McNab's (1986a) conclusion that diet (along with body mass and activity) is a

Table 4: Significant allometric and phylogenetic independent residuals for evaporative water loss of marsupials by regression for climate and geographic variables

\begin{tabular}{|c|c|c|c|c|}
\hline & \multicolumn{4}{|l|}{ Regression } \\
\hline & Variable $^{\mathrm{a}}$ & Slope & $r^{2}$ & $P$ \\
\hline Conventional & Rainfall variability & $-.274 \pm .083$ & .344 & .003 \\
\hline $\mathrm{AC}$ & Rainfall variability & $-.218 \pm .096$ & .198 & .034 \\
\hline PVR & Rainfall variability & $-.221 \pm .080$ & .267 & .012 \\
\hline PGLS & Rainfall variability & $-.292 \pm .083$ & .369 & .002 \\
\hline
\end{tabular}

principal factor influencing BMR in marsupials. He suggested that an absence of hypermetabolic marsupials obscures any adaptation to low-energy niches (either diet or distribution). It is unclear why marsupial species that occupy niches that for eutherian mammals correspond to a high BMR (e.g., mesic habitats, vertebrate or herbivorous diets) do not have correspondingly high BMRs. However, the honey possum had a consistently higher-than-predicted BMR both before and after phylogenetic correction, which is presumably related to its mostly nectarivorous diet. Small nectarivorous birds also have high BMRs (McNab 1988).

For $C_{\text {wet }}$, ANOVA indicated significant differences between specific dietary categories (Table 3 ). Folivores consistently had low $C_{\text {wet }}$ residuals, presumably because they are exposed to the elements in treetops while feeding and a low conductance is thermally advantageous. High $C_{\text {wet }}$ residuals were associated with insectivory, even after allometric correction for the generally small body mass of insectivores. Insectivorous marsupials (daysurids and pygmy possums) generally use torpor to reduce energy expenditure (Geiser 1994, 2003), and a high $C_{\text {wet }}$ would facilitate rapid heat loss and entry into torpor. $C_{\text {wet }}$ was generally not influenced by rainfall, distribution, or climate for marsu- 
pials. This was surprising because thermal conductance is generally related to habitat in placental mammals (e.g., Scholander et al. 1950a, 1950b; Lovegrove and Heldmaier 1994) although for birds the influence of environmental variables on conductance is uncertain (see McNab 2000; Schleucher and Withers 2001).

EWL residuals were unrelated to distribution or diet (Table 4). This is surprising because we expected that EWL would be a more plastic physiological variable than $T_{\mathrm{b}}, \mathrm{BMR}$, or $C_{\text {wet }}$ and would respond more adaptively to environmental variability, particularly aridity. However, there was a strong and very consistent negative regression relationship between EWL and RV. Again, our regression analysis seems more powerful and consistent than ANOVA for detecting environmental correlates, presumably because climate data were for the capture location of the individual study animals and were quantitative rather than categorical. Arid zone mammals and birds previously have been shown to have a lower EWL than other species (Hinds and MacMillen 1985; MacMillen and Hinds 1998; Tieleman and Williams 1999, 2000, 2002). A low EWL in areas with variable and unpredictable rainfall is presumably advantageous for maintaining water balance during dry periods.
We conclude that extant marsupials are a physiologically conservative group, with few species outliers before or after phylogenetic correction, probably reflecting their lesser adaptational variability compared with placental mammals and birds. Allometric effects predominate over phylogenetic effects for those physiological variables that we have investigated. Having accounted for allometric and phylogenetic effects, there remained some correlates for $T_{\mathrm{b}}, \mathrm{BMR}, C_{\text {wet }}$, and EWL with diet, aridity of distribution, and/or climatic variables. The four different phylogenetic methods (AC, PVR, IC, PGLS) yielded similar results with respect to the major patterns that we observed for marsupial physiological traits (BMR and EWL residuals related to RV; $C_{\text {wet }}$ residuals related to diet). This consistency gives us considerable confidence in our results.

\section{Acknowledgments}

We are grateful to the following individuals for assistance with phylogenetic analysis: Dr. José Alexandre Felizola Diniz-Filho (PVR), Dr. James Rohlf (autocorrelation), Dr. Norman Draper (PGLS), and Dr. Ted Garland $\left(k^{*}\right)$.

\section{Appendix A}

Table A1: Physiological data for marsupials

\begin{tabular}{|c|c|c|c|c|c|}
\hline Species & $\begin{array}{l}\text { Body } \\
\text { Mass (g) }\end{array}$ & $\begin{array}{l}T_{\mathrm{b}} \\
\left({ }^{\circ} \mathrm{C}\right)\end{array}$ & $\begin{array}{l}\text { BMR } \\
\left(\mathrm{mL} \mathrm{O}_{2} \mathrm{~h}^{-1}\right)\end{array}$ & $\begin{array}{l}C_{\text {wet }} \\
\left(\mathrm{J} \mathrm{h} \mathrm{h}^{-1}{ }^{\circ} \mathrm{C}^{-1}\right)\end{array}$ & $\begin{array}{l}\text { EWL } \\
\left(\mathrm{mg} \mathrm{h}^{-1}\right)\end{array}$ \\
\hline Acrobates pygmaeus & 14 & 34.9 & 15 & 113 & \\
\hline Antechinomys laniger & 26 & 35.7 & 26 & 107 & \\
\hline Antechinus stuartii & 28 & 35.1 & 34 & 152 & 96.5 \\
\hline Bettongia gaimardi & 1,385 & 35.6 & 641 & 2,311 & \\
\hline Bettongia penicillata & 1,018 & 37.2 & 561 & 1,657 & \\
\hline Burramys parvus & 44 & 36.1 & 37 & & \\
\hline Caluromys derbianus & 357 & 34 & 204 & 452 & \\
\hline Cercartetus concinnus & 19 & 34.4 & 22 & 70.3 & \\
\hline Cercartetus lepidus & 13 & 33.7 & 19 & 56.2 & \\
\hline Cercartetus nanus & 70 & 34.9 & 60 & 197 & $140^{\mathrm{a}}$ \\
\hline Chironectes minimus & 934 & 35 & 456 & 1,052 & \\
\hline Dasuroides byrnei & 102 & 35.4 & 83 & 208 & 146 \\
\hline Dasycercus cristicauda & 101 & 36.6 & 51 & 147 & 146 \\
\hline Dasyurus geoffroyii & 1,354 & 36.2 & 569 & 980 & \\
\hline Dasyurus hallucatus & 558 & 35.9 & 243 & 831 & \\
\hline Dasyurus maculatus & 1,782 & 36.9 & 587 & 1,182 & \\
\hline Dasyurus viverrinus & 982 & 35.9 & 396 & 1,352 & 1,072 \\
\hline Didelphis marsupialis & 1,164 & 35 & 570 & 1,217 & \\
\hline Didelphis virginiana & 2,468 & 35 & 826 & 1,561 & \\
\hline Echymipera kalubu & 695 & 35 & 340 & 1,369 & \\
\hline Echymipera rufescens & 946 & 35.2 & 432 & 1,350 & \\
\hline Isoodon auratus & 428 & 33.8 & 150 & 792 & $528^{\mathrm{b}}$ \\
\hline Isoodon macrourus & 1,216 & 35.3 & 521 & 1,365 & $1,075^{\mathrm{c}}$ \\
\hline Isoodon obesulus & 718 & 33.9 & 222 & 1,139 & $734^{\mathrm{b}}$ \\
\hline Lagorchestes conspicillatus & 2,660 & 36 & 851 & 1,123 & $2,128^{\mathrm{d}}$ \\
\hline
\end{tabular}


Table A1 (Continued)

\begin{tabular}{|c|c|c|c|c|c|}
\hline Species & $\begin{array}{l}\text { Body } \\
\text { Mass (g) }\end{array}$ & $\begin{array}{l}T_{\mathrm{b}} \\
\left({ }^{\circ} \mathrm{C}\right)\end{array}$ & $\begin{array}{l}\text { BMR } \\
\left(\mathrm{mL} \mathrm{O}_{2} \mathrm{~h}^{-1}\right)\end{array}$ & $\begin{array}{l}C_{\text {wet }} \\
\left(\mathrm{J} \mathrm{h} \mathrm{h}^{-1}{ }^{\circ} \mathrm{C}^{-1}\right)\end{array}$ & $\begin{array}{l}\text { EWL } \\
\left(\mathrm{mg} \mathrm{h}^{-1}\right)\end{array}$ \\
\hline Lasiorhinus latifrons & 29,917 & 35.3 & 2,992 & 7,998 & \\
\hline Lutreolina crassicaudata & 812 & 35.8 & 406 & 865 & \\
\hline Macropus eugenii & 4,878 & 36.5 & 1,390 & 2,074 & $2,728^{\mathrm{e}}$ \\
\hline Macropus giganteus & $26,000^{\mathrm{f}}$ & $36.5^{\mathrm{f}}$ & $5,546^{\mathrm{f}}$ & & \\
\hline Macropus robustus & 29,300 & 36.1 & 5,572 & 18,846 & $13,440^{\mathrm{g}}$ \\
\hline Macropus rufus & $28,745^{\mathrm{f}}$ & $35.8^{\mathrm{f}}$ & $5,662^{\mathrm{f}}$ & $9,822^{\mathrm{f}}$ & $11,200^{\mathrm{g}}$ \\
\hline Macrotis lagotis & 1,294 & 35 & 455 & 1,249 & $854^{\mathrm{c}}$ \\
\hline Marmosa microtarsus & 13 & 35 & 19 & 67.9 & \\
\hline Marmosa robinsoni & 122 & 34 & 97 & 272 & \\
\hline Metachirus nudicaudatus & 336 & 35 & 205 & 561 & \\
\hline Monodelphis brevicaudata & 76 & 33.7 & 60 & 235 & \\
\hline Monodelphis domestica & 93 & 32.6 & 63 & 411 & \\
\hline Myrmecobius fasciatus & $519^{\mathrm{h}}$ & $34.1^{\mathrm{h}}$ & $143^{\mathrm{h}}$ & $1,071^{\mathrm{h}}$ & $300^{\mathrm{h}}$ \\
\hline Ningaui yvonnae & 12 & 34.4 & 16 & 93.3 & \\
\hline Notoryctes caurinus & 34 & 30.6 & 22 & 344 & \\
\hline Perameles gunni & 838 & 35.2 & 421 & 1,633 & $892^{\mathrm{b}}$ \\
\hline Perameles nasuta & 665 & 36.1 & 319 & 916 & $1,171^{\mathrm{c}}$ \\
\hline Petauroides volans & 1,000 & & 428 & & \\
\hline Petaurus breviceps & 127 & 35.9 & 90 & 281 & \\
\hline Phalanger maculatus & 4,250 & 34.6 & 1,104 & 1,794 & $1,981^{\mathrm{i}}$ \\
\hline Phascogale tapoatafa & 157 & 37.4 & 127 & 692 & 404 \\
\hline Phascolarctos cinereus & 4,765 & 35.7 & 1,047 & 2,011 & \\
\hline Philander opossum & 751 & 35.8 & 338 & 996 & \\
\hline Planigale gilesi & 9 & 35.1 & 12 & 99.5 & \\
\hline Planigale ingrami & 7 & 34.5 & 11 & 94.6 & \\
\hline Planigale maculata & 9 & 34.2 & 11 & & 50.6 \\
\hline Potorous tridactylus & 1,033 & 35.9 & 413 & 820 & $1,120^{c}$ \\
\hline Pseudantechinus macdonnellensis & 43 & 34.2 & 27 & 121 & 115 \\
\hline Sarcophilus harrisii & 5,775 & 35.9 & 1,503 & 2,438 & 8,135 \\
\hline Setonix brachyurus & 2,940 & 36.8 & 891 & 1,300 & \\
\hline Sminthopsis crassicaudata & 16 & 35.2 & 25 & 120 & 91.3 \\
\hline Sminthopsis macroura & 23 & 33.8 & 24 & 187 & \\
\hline Sminthopsis murina & 19 & 35 & 21 & & \\
\hline Tarsipes rostratus & 10 & 36.6 & 29 & 88.2 & \\
\hline Thylamys elegans & $31^{j}$ & & $20^{j}$ & & \\
\hline Trichosurus vulpecula & 2,004 & 36 & 731 & 1,370 & $1,406^{\mathrm{k}}$ \\
\hline
\end{tabular}

Note. Body mass is for BMR data. Body mass, $T_{\mathrm{b}}$, BMR, and $C_{\text {wet }}$ data are from Withers et al. (2000) unless otherwise noted. EWL data are from Hinds and MacMillen (1986) unless otherwise noted.

${ }^{\text {a }}$ From Bartholomew and Hudson 1962.

${ }^{\mathrm{b}}$ From Larcombe 2004.

${ }^{c}$ From Hulbert and Dawson 1974.

${ }^{\mathrm{d}}$ From Dawson and Bennett 1978.

${ }^{\mathrm{e}}$ From Dawson et al. 1969.

${ }^{\mathrm{f}}$ From Dawson et al. 2000.

${ }^{g}$ From Dawson 1973.

${ }^{\mathrm{h}}$ From Cooper and Withers 2002.

${ }^{\text {i }}$ From Dawson and Degabriele 1973.

j From Nespolo et al. 2002.

${ }^{k}$ From Dawson 1969. 


\section{Appendix B}

Table B1: Diet, habitat aridity based on distribution, and habitat data for marsupials

\begin{tabular}{|c|c|c|c|c|c|c|c|c|c|}
\hline Species & Diet & Habitat Aridity ${ }^{a}$ & MAR & RV & $T_{\text {cold }}$ & $T_{\text {hot }}$ & $T_{\mathrm{a}}$ & Alt & Lat \\
\hline Acrobates pygmaeus & Omnivore & SA/M (M) & 906.3 & .165 & 7.8 & 21.1 & 14.4 & 113 & 37.57 \\
\hline Antechinomys laniger & Insectivore & SA/M (M) & 429.6 & .087 & 16.5 & 30.1 & 24.5 & 344 & 20.43 \\
\hline Antechinus stuartii & Insectivore & SA/M (M) & $1,096.8$ & .209 & 12.6 & 22.3 & 17.5 & 33 & 35.55 \\
\hline Burramys parvus & Omnivore & SA/M (M) & 632.0 & .148 & 5.5 & 20.3 & 12.9 & 577 & 35.18 \\
\hline Caluromys derbianus & Omnivore & $\mathrm{SA} / \mathrm{M}(\mathrm{M})$ & $1,775.6$ & .052 & 26.8 & 28.5 & 27.4 & 15 & 8.97 \\
\hline Cercartetus concinnus & Omnivore & SA/M (A/SA) & 319.0 & .405 & 10.9 & 23.6 & 17.1 & 61 & 33.36 \\
\hline Cercartetus lepidus & Omnivore & $\mathrm{SA} / \mathrm{M}(\mathrm{M})$ & 369.0 & .247 & 9.6 & 21.9 & 15.7 & 88 & 35.45 \\
\hline Cercartetus nanus & Nectivore & SA/M (M) & $1,169.3$ & .208 & 3.2 & 12.5 & 7.8 & 589 & 42.00 \\
\hline Chironectes minimus & Omnivore & SA/M (M) & $1,775.6$ & .052 & 26.8 & 28.5 & 27.4 & 15 & 9.00 \\
\hline Dasuroides byrnei & Vertebrativore & $\mathrm{A}(\mathrm{A} / \mathrm{SA})$ & 159.6 & .481 & 13.5 & 31.1 & 22.9 & 47 & 25.08 \\
\hline Dasycercus cristicauda & Vertebrativore & $\mathrm{A}(\mathrm{A} / \mathrm{SA})$ & 219.3 & .397 & 11.5 & 29.4 & 21.1 & 488 & 25.25 \\
\hline Dasyurus geoffroyii & Vertebrativore & $\mathrm{SA} / \mathrm{M}(\mathrm{M})$ & 952.6 & .827 & 9.9 & 15.5 & 21.9 & 160 & 31.59 \\
\hline Dasyurus hallucatus & Vertebrativore & SA/M (M) & 898.7 & .593 & 17.8 & 26.7 & 22.9 & 75 & 24.09 \\
\hline Dasyurus maculatus & Vertebrativore & SA/M (M) & 565.3 & .0163 & 9.6 & 20.0 & 14.9 & 113 & 37.49 \\
\hline Dasyurus viverrinus & Insectivore & SA/M (M) & 684.6 & .236 & 6.6 & 16.9 & 11.6 & 170 & 42.00 \\
\hline Didelphis marsupialis & Omnivore & SA/M (M) & $1,775.6$ & .052 & 26.8 & 28.5 & 27.4 & 15 & 9.00 \\
\hline Didelphis virginiana & Omnivore & $\mathrm{SA} / \mathrm{M}(\mathrm{M})$ & $1,385.7$ & .172 & 5.3 & 25.35 & 15.4 & 356 & 13.41 \\
\hline Echymipera kalubu & Omnivore & SA/M (M) & $2,477.7$ & .253 & 16.0 & 17.3 & 16.8 & 1631 & 5.00 \\
\hline Echymipera rufescens & Omnivore & SA/M (M) & $2,477.7$ & .253 & 16.0 & 17.3 & 16.8 & 1,631 & 5.00 \\
\hline Isoodon auratus & Omnivore & SA/M (M) & 319.1 & .907 & 20.7 & 30.2 & 25.9 & 63 & 20.47 \\
\hline Isoodon macrourus & Omnivore & $\mathrm{SA} / \mathrm{M}(\mathrm{M})$ & $1,992.5$ & .970 & 21.1 & 27.6 & 24.7 & 7 & 16.55 \\
\hline Isoodon obesulus & Omnivore & $\mathrm{SA} / \mathrm{M}(\mathrm{M})$ & 871.0 & .928 & 13.9 & 23.3 & 17.7 & 15 & 32.09 \\
\hline Lagorchestes conspicillatus & Folivore & SA/M (A/SA) & 319.1 & .907 & 20.7 & 30.2 & 25.9 & 63 & 20.47 \\
\hline Lasiorhinus latifrons & Herbivore & $\mathrm{A}(\mathrm{A} / \mathrm{SA})$ & 262.0 & .200 & 9.0 & 21.6 & 15.0 & 31 & 34.21 \\
\hline Lutreolina crassicaudata & Vertebrativore & SA/M (M) & 215.6 & .302 & 2.3 & 17.6 & 9.8 & 888 & 39.03 \\
\hline Macropus eugenii & Herbivore & $\mathrm{SA} / \mathrm{M}(\mathrm{M})$ & 488.1 & .565 & 11.5 & 19.3 & 15.3 & 20 & 35.45 \\
\hline Macropus giganteus & Herbivore & SA/M (A/SA) & 250.0 & .102 & 10.2 & 25.5 & 18.0 & 315 & 33.51 \\
\hline Macropus robustus & Herbivore & $\mathrm{A}(\mathrm{A} / \mathrm{SA})$ & 250.0 & .102 & 10.2 & 25.5 & 18.0 & 315 & 33.51 \\
\hline Macropus rufus & Herbivore & A (A/SA) & 251.8 & .101 & 10.2 & 25.0 & 17.3 & 315 & 31.57 \\
\hline Macrotis lagotis & Omnivore & $\mathrm{A}(\mathrm{A} / \mathrm{SA})$ & 219.3 & .397 & 11.5 & 29.4 & 21.1 & 488 & 25.25 \\
\hline Marmosa microtarsus & Omnivore & $\mathrm{SA} / \mathrm{M}(\mathrm{M})$ & $1,423.1$ & .594 & 15.1 & 21.6 & 18.6 & 792 & 23.50 \\
\hline Marmosa robinsoni & Omnivore & SA/M (M) & $1,775.6$ & .52 & 26.8 & 28.5 & 27.4 & 15 & 9.00 \\
\hline Metachirus nudicaudatus & Omnivore & $\mathrm{SA} / \mathrm{M}(\mathrm{M})$ & $1,775.6$ & .52 & 26.8 & 28.5 & 27.4 & 15 & 9.00 \\
\hline Monodelphis brevicaudata & Omnivore & SA/M (M) & $1,368.1$ & .356 & 23.3 & 25.7 & 25.1 & 160 & 9.73 \\
\hline Monodelphis domestica & Omnivore & SA/M (M) & $1,343.0$ & .978 & 26.1 & 29.4 & 27.3 & 74 & 34.81 \\
\hline Myrmecobius fasciatus & Insectivore & A (A/SA) & 506.8 & .707 & 10.3 & 22.8 & 16.1 & 338 & 32.46 \\
\hline Ningaui yvonnae & Insectivore & A (A/SA) & 369.0 & .247 & 9.6 & 21.9 & 15.7 & 88 & 35.45 \\
\hline Notoryctes caurinus & Insectivore & A (A/SA) & 262.9 & 1.050 & 17.8 & 32.7 & 26.1 & 294 & 22.03 \\
\hline Perameles gunni & Omnivore & SA/M (M) & 561.0 & .125 & 5.3 & 15.2 & 10.3 & 400 & 42.55 \\
\hline Perameles nasuta & Omnivore & $\mathrm{SA} / \mathrm{M}(\mathrm{M})$ & $1,210.6$ & .218 & 12.4 & 22.3 & 17.7 & 40 & 33.51 \\
\hline Petauroides volans & Folivore & SA/M (M) & $1,677.8$ & .414 & 13.0 & 23.2 & 18.6 & 5 & 30.18 \\
\hline Petaurus breviceps & Omnivore & $\mathrm{SA} / \mathrm{M}(\mathrm{M})$ & $1,210.6$ & .218 & 12.4 & 22.3 & 17.7 & 40 & 33.00 \\
\hline Phalanger maculatus & Omnivore & SA/M (M) & $1,992.5$ & .970 & 21.1 & 27.6 & 24.7 & 7 & 16.55 \\
\hline Phascogale tapoatafa & Insectivore & $\mathrm{SA} / \mathrm{M}(\mathrm{M})$ & 418.7 & .295 & 8.6 & 21.2 & 14.8 & 133 & 36.32 \\
\hline Philander opossum & Omnivore & SA/M (M) & $1,775.6$ & .052 & 26.8 & 28.5 & 27.4 & 15 & 9.00 \\
\hline Planigale gilesi & Insectivore & SA/M (M) & 162.1 & .277 & 11.8 & 29.2 & 20.7 & 51 & 28.22 \\
\hline Planigale ingrami & Insectivore & $\mathrm{SA} / \mathrm{M}(\mathrm{M})$ & 853.2 & 1.210 & 20.9 & 32.1 & 27.7 & 205 & 33.49 \\
\hline Potorous tridactylus & Fungivore & SA/M (M) & $1,274.9$ & .297 & 13.2 & 22.4 & 18.1 & 24 & 33.25 \\
\hline Pseudantechinus macdonnellensis & Insectivore & $\mathrm{A}(\mathrm{A} / \mathrm{SA})$ & 219.3 & .397 & 11.5 & 29.4 & 21.1 & 488 & 25.25 \\
\hline Sarcophilus harrissi & Vertebrativore & $\mathrm{SA} / \mathrm{M}(\mathrm{M})$ & 684.6 & .236 & 6.6 & 16.9 & 11.6 & 170 & 41.26 \\
\hline Setonix brachyurus & Folivore & SA/M (M) & 702.1 & .952 & 14.4 & 22.6 & 18.3 & 12 & 32.00 \\
\hline Sminthopsis crassicaudata & Insectivore & $\mathrm{A}(\mathrm{A} / \mathrm{SA})$ & 251.8 & .101 & 10.2 & 25.0 & 17.3 & 315 & 31.57 \\
\hline
\end{tabular}


Table B1 (Continued)

\begin{tabular}{|c|c|c|c|c|c|c|c|c|c|}
\hline Species & Diet & Habitat Aridity $^{a}$ & MAR & RV & $T_{\text {cold }}$ & $T_{\text {hot }}$ & $T_{\mathrm{a}}$ & Alt & Lat \\
\hline Sminthopsis macroura & Insectivore & $\mathrm{A}(\mathrm{A} / \mathrm{SA})$ & 803.1 & .205 & 5.1 & 17.5 & 11.3 & 503 & 37.45 \\
\hline Sminthopsis murina & Insectivore & SA/M (A/SA) & $1,096.8$ & .209 & 12.6 & 22.3 & 17.5 & 33 & 32.55 \\
\hline Tarsipes rostratus & Nectarivore & SA/M (M) & 642.8 & .498 & 11.5 & 21.5 & 16.5 & 233 & 34.04 \\
\hline Thylamys elegans & Omnivore & $\mathrm{SA} / \mathrm{M}(\mathrm{M})$ & 324.9 & 1.100 & 7.9 & 20.3 & 14.0 & 475 & 70.42 \\
\hline Trichosurus vulpecula & Folivore & SA/M (M) & $1,210.6$ & .218 & 12.4 & 22.3 & 17.7 & 40 & 33.51 \\
\hline
\end{tabular}

Sources. Data from National Climate Data Center in Asheville, North Carolina (http://ingrid.ldgo.columbia.edu/SOURCES/.NOAA/.NCDC); Strahan (1991); and Walker (1975).

Note. Habitat data: MAR = mean annual rainfall $(\mathrm{mm}) ; \mathrm{RV}=$ within-year rainfall variability; $T_{\text {cold }}=$ mean temperature of the coldest month $\left({ }^{\circ} \mathrm{C}\right) ; T_{\text {hot }}=$ mean temperature of the hottest month $\left({ }^{\circ} \mathrm{C}\right) ; T_{\mathrm{a}}=$ mean annual temperature $\left({ }^{\circ} \mathrm{C}\right)$; Alt $=$ altitude $(\mathrm{m})$; Lat $=$ latitude $\left({ }^{\circ}\right)$.

${ }^{\mathrm{a}} \mathrm{A}=\operatorname{arid}(\leq 250 \mathrm{~mm}$ annual rainfall); $\mathrm{SA} / \mathrm{M}=$ semiarid $/ \mathrm{mesic}(>250 \mathrm{~mm}$ annual rainfall). In parentheses, $\mathrm{A} / \mathrm{SA}=$ arid $/ \mathrm{semiarid}(\leq 500$ $\mathrm{mm}$ annual rainfall); $\mathrm{M}=$ mesic ( $>500 \mathrm{~mm}$ annual rainfall).

\section{Literature Cited}

Aschoff J. 1981. Thermal conductance in mammals and birds: its dependence on body size and circadian phase. Comp Biochem Physiol A 69:611-619.

Asher R.J., I. Horovitz, and M.R. Sánchez-Villagra. 2004. First combined cladistic analysis of marsupial mammal interrelationships. Mol Phylogenet Evol 33:240-250.

Bartholomew G.A. and J.W. Hudson. 1962. Hibernation, aestivation, temperature regulation, evaporative water loss, and heart rate of the pygmy possum, Cercartetus nanus. Physiol Zool 29:94-107.

Bennett P.M. and P.H. Harvey. 1987. Active and resting metabolism in birds: allometry, phylogeny and ecology. J Zool (Lond) 213:327-363.

Blomberg S.P., T. Garland, and A.R. Ives. 2003. Testing for phylogenetic signal in comparative data: behavioural traits are more labile. Evolution 57:717-745.

Bradley S.R. and D.R. Deavers. 1980. A re-examination of the relationship between thermal conductance and body weight in mammals. Comp Biochem Physiol A 65:465-476.

Bradley W.G. and M.K. Yousef. 1972. Small mammals in the desert. Pp. 127-142 in M.K. Yousef, S.M. Horvath, and R.W. Bullard, eds. Physiological Adaptations: Desert and Mountain. Academic Press, New York.

Brody P.F. and R.C. Procter. 1932. Relation between basal metabolism and mature body weight in different species of mammals and birds. Univ Mo Agric Exp Stn Res Bull 116: 89-101.

Calder W.A. 1984. Size, Function and Life History. Harvard University Press, Cambridge, MA.

Cheverud J.M. and M.M. Dow. 1985. An autocorrelation analysis of genetic variation due to lineal fission in social groups of Rhesus macaques. Am J Phys Anthropol 67:113-121.

Cooper C.E. and P.C. Withers. 2002. Metabolic physiology of the numbat (Myrmecobius fasciatus). J Comp Physiol B 172: 669-675.

Crawford E.C. and R.C. Lasiewski. 1968. Oxygen consumption and respiratory evaporation in the emu and rhea. Condor 70:333-339.

Dawson T.J. 1969. Temperature regulation and evaporative water loss in the brush-tailed possum Trichosurus vulpecula. Comp Biochem Physiol 28:401-407.

- 1973. Thermoregulatory responses of the arid zone kangaroos Megaleia rufa and Macropus robustus. Comp Biochem Physiol A 46:153-169.

Dawson T.J. and R. Degabriele. 1973. The cuscus (Phalanger maculatus) —a marsupial sloth? J Comp Physiol 83:41-50.

Dawson T.J., M.J.S. Denney, and A.J. Hulbert. 1969. Thermal balance of the macropod marsupial Macropus eugenii. Comp Biochem Physiol 31:645-653.

Dawson T.J. and A.J. Hulbert. 1970. Standard metabolism, body temperature and surface areas of Australian marsupials. Am J Physiol 218:1233-1238.

Dawson T.J., A.J Munn, C.E. Blaney, A. Krockenberger, and S.K. Maloney. 2000. Ventilatory accommodation of oxygen demand and respiratory water loss in kangaroos from mesic and arid environments, the eastern grey kangaroo (Macropus giganteus) and the red kangaroo (Macropus rufus). Physiol Biochem Zool 73:382-388.

Dawson W.R. and A.F. Bennett. 1978. Energy metabolism and thermoregulation of the spectacled hare wallaby (Lagorchestes conspicillatus). Physiol Zool 51:114-130.

Diniz-Filho J.A.F., C.E.R. De Sant'Ana, and L.M. Bini. 1998. An eigenvector method for estimating phylogenetic inertia. Evolution 52:1247-1262.

Draper N. and H. Smith. 1998. Applied Regression Analysis. Wiley, New York.

Edwards D. and M. Westerman. 1995. The molecular relationships of possum and glider families as revealed by DNADNA hybridisations. Aust J Zool 43:231-240.

Elgar M.A. and P.H. Harvey. 1987. Basal rates in mammals: allometry, phylogeny and ecology. Funct Ecol 1:25-36.

Felsenstein J. 1985. Phylogenies and the comparative method. Am Nat 125:1-15.

Garland T. and S.C. Adolph. 1994. Why not to do two-species 
comparative studies: limitations on inferring adaptation. Physiol Zool 67:797-828.

Garland T. and A.R. Ives. 2000. Using the past to predict the present: confidence intervals for regression equations in phylogenetic comparative methods. Am Nat 155:346-364.

Garland T., P.E. Midford, and A.R. Ives. 1999. An introduction to phylogenetically based statistical methods, with a new method for confidence intervals on ancestral values. Am Zool 39:374-388.

Geiser F. 1994. Hibernation and daily torpor in marsupials: a review. Aust J Zool 42:1-16.

- 2003. Thermal biology and energetics of carnivorous marsupials. Pp. 238-253 in M. Jones, C. Dickman, and M. Archer, eds. Predators with Pouches: The Biology of Carnivorous Marsupials. CSIRO, Collingwood, Australia.

Grubbs F. 1969. Procedures for detecting outlying observations in samples. Technometrics 11:1-21.

Hart J.S. 1971. Rodents. Pp. 1-149 in G.C. Whittow, ed. Comparative Physiology of Thermoregulation. Vol. 2. Mammals. Academic Press, London.

Harvey P.H. and M.D. Pagel. 1991. The Comparative Method in Evolutionary Biology. Oxford University Press, New York.

Harvey P.H., M.D. Pagel, and Rees J.A. 1991. Mammalian metabolism and life histories. Am Nat 137:556-566.

Hayssen V. and R.C. Lacy. 1985. Basal metabolic rates in mammals: taxonomic differences in the allometry of BMR and body mass. Comp Biochem Physiol 4:741-754.

Hinds D.S. and R.E. MacMillen. 1985. Scaling of energy metabolism and evaporative water loss in heteromyid rodents. Physiol Zool 58:282-298.

- 1986. Scaling of evaporative water loss in marsupials. Physiol Zool 59:1-9.

Hulbert A.J. and T.J. Dawson. 1974. Water metabolism in perameloid marsupials from different environments. Comp Biochem Physiol A 47:617-633.

Irving L. and J. Krog. 1954. Body temperature of arctic and subarctic birds and mammals. J Appl Physiol 6:667-680.

Kirsch J.A.W. 1977. The comparative serology of Marsupialia. Nature 217:418-420.

Kirsch J.A.W., F.J. Lapointe, and M.S. Springer. 1997. The DNAhybridisation studies of marsupials and their implications for metatherian classification. Aust J Zool 45:211-280.

Kirsch J.A.W. and R.E. Palma. 1995. DNA/DNA-hybridisation studies of carnivorous marsupials. V. A further estimate of relationships among opossums (Marsupialia: Didelphidae). Mammalogy 59:403-425.

Kleiber M. 1932. Body size and metabolism. Hilgardia 6:315353.

Krajewski C., S. Wroe, and M. Westerman. 2000. Molecular evidence for the pattern and timing of cladogenesis in dasyurid marsupials. Zool J Linn Soc 130:375-404.

Larcombe A. 2004. Comparative Metabolic, Thermoregulatory and Ventilatory Physiology of Bandicoots (Peramelidae).
PhD thesis. School of Animal Biology, University of Western Australia, Perth.

Lasiewski R.C. and W.R. Dawson. 1967. A re-examination of the relation between standard metabolic rate and body weight in birds. Condor 69:13-23.

Lovegrove B.G. 2000. The zoogeography of mammalian basal metabolic rate. Am Nat 156:201-219.

- 2003. The influence of climate on the basal metabolic rate of small mammals: a slow-fast metabolic continuum. J Comp Physiol B 173:87-112.

Lovegrove B.G. and G. Heldmaier. 1994. The amplitude of circadian body temperature rhythms in three rodents (Aethomys namaquensis, Thallomys paedulcus and Cryptomys damarensis) along an arboreal-subterranean gradient. Aust J Zool 42:65-78.

MacMillen R.E. and D.S. Hinds. 1998. Water economy of granivorous birds: California house finches. Condor 100:493503.

Martins E.P. 1996. Phylogenies, spatial autoregression, and the comparative method: a computer simulation test. Evolution 50:1750-1765.

Martins E.P. and T.P. Hansen. 1997. Phylogenies and the comparative method: a general approach to incorporating phylogenetic information into the analysis of interspecific data. Am Nat 149:646-667.

McKechnie A.E. and B.E. Wolf. 2004. The allometry of avian basal metabolic rate: good predictions need good data. Physiol Biochem Zool 77:502-521.

McNab B.K. 1966. The metabolism of fossorial rodents: a study of convergence. Ecology 47:712-733.

- 1970. Body weight and the energetics of temperature regulation. J Exp Biol 53:329-348.

- 1980. Food habits, energetics, and the population biology of mammals. Am Nat 116:106-124.

- 1984. Physiological convergence amongst ant-eating and termite-eating mammals. J Zool (Lond) 203:485-510.

- 1986a. Food habits, energetics, and the reproduction of marsupials. J Zool (Lond) 208:595-614.

- 1986b. The influence of food habits on the energetics of eutherian mammals. Ecol Monogr 56:1-19.

- 1988. Food habits and the basal rate of metabolism in birds. Oecologia 77:343-349.

- 2000. Influence of body mass, climate and distribution on energetics of South Pacific pigeons. Comp Biochem Physiol A 127:309-329.

- 2002. The Physiological Ecology of Vertebrates: A View from Energetics. Cornell University Press, Ithaca, NY.

Morrison P.R. and F.A. Ryser. 1952. Weight and body temperature in mammals. Science 116:231-232.

Nespolo R.F., L.D. Bacigalupe, P. Sabat, and F. Bozinovic. 2002. Interplay among energy metabolism, organ mass and digestive enzyme activity in the mouse-opossum Thylamys elegans: the role of thermal acclimation. J Exp Biol 205:2697-2703. 
Neter J., M.H. Kutner, W. Wasserman, and C.J. Nachtsheim. 1996. Applied Linear Statistical Models. 4th ed. McGrawHill, New York.

Nilsson M.A., U. Arnason, P.B.S. Spencer, and A. Janke. 2004. Marsupial relationships and a timeline for marsupial radiation in South Gondwana. Gene 340:189-196.

Rezende E.L., F. Bozinovic, and T. Garland. 2004. Climatic adaptation and the evolution of basal and maximal rates of metabolism in rodents. Evolution 58:1361-1374.

Rohlf F.J. 2001. Comparative methods for the analysis of continuous variables: geometric interpretations. Evolution 55: 2143-2160.

Schleucher E. and P.C. Withers. 2001. Re-evaluation of the allometry of wet thermal conductance for birds. Comp Biochem Physiol A 129:821-827.

- 2002. Metabolic and thermal physiology of pigeons and doves. Physiol Biochem Zool 75:439-450.

Schmidt-Nielsen K. 1984. Scaling: Why Is Animal Size So Important? Cambridge University Press, New York.

Scholander P.F., R. Hock, V. Walters, F. Johnson, and L. Irving. $1950 a$. Heat regulation in some arctic and tropical mammals and birds. Biol Bull 99:237-258.

Scholander P.F., V. Walters, R. Hock, and L. Irving. 1950b. Body insulation of some arctic and tropical mammals and birds. Biol Bull 99:225-236.

Stahl W.L. 1967. Scaling of respiratory variables in mammals. J Appl Physiol 22:453-460.
Strahan R., ed. 1991. The Australian Museum Complete Book of Australian Mammals: National Photographic Index of Australian Wildlife. Cornstalk, North Ryde, Australia.

Stefansky W. 1972. Rejecting outliers in factorial designs. Technometrics 14:469-479.

Tieleman B.I. and J.B. Williams. 1999. The role of hyperthermia in the water economy of desert birds. Physiol Biochem Zool 72:87-100.

- 2000. The adjustment of avian metabolic rates and water fluxes to desert environments. Physiol Biochem Zool 73:461-479.

- 2002. Cutaneous and respiratory water loss in larks from arid and mesic environments. Physiol Biochem Zool 75:590-599.

Walker E.P. 1975. Mammals of the World. Johns Hopkins University Press, London.

White C.R. and R.S. Seymour. 2003. Mammalian basal metabolic rate is proportional to body mass. Proc Natl Acad Sci USA 100:4046-4049.

Williams J.B. 1996. A phylogenetic perspective of evaporative water loss in birds. Auk 113:457-472.

Withers P.C., G.G. Thompson, and R.S. Seymour. 2000. Metabolic physiology of the north-western marsupial mole, Notoryctes caurinus (Marsupialia: Notorycidae). Aust J Zool 48: 241-258.

Zar J.H. 1999. Biostatistical Analysis. Prentice Hall, Englewood Cliffs, NJ. 